\title{
Qualidade da água superficial de reservatórios temporários localizados entre a região semiárida e o litoral do Nordeste Brasileiro
}

\author{
Surface water quality of temporary reservoirs located between the semi-arid region and the \\ Brazilian northeast coast
}

\author{
Thiago Farias Nobrega' \\ Raquel Franco Souza' \\ Guilherme Fulgencio Medeiros'
}

\section{Resumo}

Na bacia hidrográfica do Rio Doce (BHRD), Nordeste Brasileiro, verifica-se ocupação não planejada, poluição e elevado déficit hídrico, tais fatores foram agravados pela seca que se iniciou em 2012, o que pode implicar em conflitos e distúrbios sociais. O objetivo deste trabalho foi analisar características físicas, químicas e ecotoxicológicas em relação a precipitação mensal, ocupação do solo e critérios de qualidade de água, de amostras de água de oito reservatórios superficiais, de duas sub-bacias, em agosto de 2016. Na região estudada verificou-se que os valores de condutividade elétrica e os teores de dureza, $\mathrm{Cd}$, Ni e cloreto foram significativamente diferentes entre as subbacias, isto provavelmente se deve à fatores naturais, como a geologia predominante em cada sub-bacia. Em todas as estações de amostragem os metais $\mathrm{Cd}, \mathrm{Pb}, \mathrm{Cu}$ e $\mathrm{Zn}$ apresentam inconformidades aos critérios de qualidade de água para proteção da vida aquática, para consumo humano e criação de animais foi o $\mathrm{Pb}$ e a salinidade para o uso na irrigação. Além disso os efeitos tóxicos à reprodução de M. micrura e C. silvestrii, provavelmente causados por $\mathrm{Pb}, \mathrm{Cu}, \mathrm{Zn}$, indicam que o uso de espécies nativas para analisar amostras ambientais é indispensável para maior representatividade e relevância da pesquisa.

Palavras-chave: Ecotoxicologia aquática, Moina micrura, Geoquímica ambiental

\section{Abstract}

In Doce River watershed (DRW), Northeast Brazil, there is unplanned occupation, pollution and high water deficit, such factors were aggravated by the drought that started in 2012, which could imply conflicts and social disturbances. The purpose of this work was to analyze physical, chemical and ecotoxicological characteristics in relation to monthly precipitation, soil occupancy and water quality criteria, of samples from eight superficial reservoirs, of two sub basin, in august 2016. In the region studied was verified that the values of electrical conductivity, hardness content, Cd, Ni and chloride content were significantly different among the sub basins, this is probably due to the natural factors, such as the predominant geology in each sub basin. In all sampling stations the metals $\mathrm{Cd}, \mathrm{Pb}, \mathrm{Cu}$ and $\mathrm{Zn}$ shows disconformity to the water quality criteria to protect aquatic biota, for human consumption and livestock was the metal $\mathrm{Pb}$ and the salinity for use in irrigation. In addition, the toxic effects to the reproduction of $\mathrm{M}$. Micrura and $\mathrm{C}$. Silvestrii, was probably caused by $\mathrm{Pb}, \mathrm{Cu}, \mathrm{Zn}$, indicate that the use of native species to analyze environmental samples is indispensable for increase the representativeness and relevance of research.

Keywords: Aquatic ecotoxicology, Moina micrura, Environmental geochemistry 


\section{Introdução}

Em estimativas do Ministério de Integração Nacional do Brasil, estima-se perdas na ordem de 6 bilhões de dólares no setor de agricultura e mais de 1100 cidades enfrentam conflitos e distúrbios sociais, devido impactos da seca (Marengo et al., 2017), ainda segundo estes autores a seca atual começou em 2012, com sua maior intensidade em 2012-2013 e menor intensidade em 2015. Os objetos deste estudo foram as sub-bacias do Rio do Mudo e Rio Guajiru, que compõem a bacia hidrográfica do Rio Doce (BHRD) (figura 01), compreendida entre o semiárido e o litoral. Os corpos hídricos na porção leste desta bacia são importantes para a manutenção e o desenvolvimento socioeconômico de uma área com grande densidade populacional e relativa atividade industrial, que inclui a zona norte de Natal (Melo et al., 2010). Ao longo da bacia do Rio Doce verifica-se a presença de atividades agrícolas, que se concentram mais a oeste, onde estão localizadas as cabeceiras dos rios do Mudo e Guajiru.

Dados do IBGE (2011) mostram a porção oeste da área estudada com maior número de residentes na zona rural. Segundo IBGE (2011) na maioria dos municípios do Brasil, os serviços de saneamento e esgotamento sanitário são inadequados, o número de usuários da rede de esgoto sanitário é no mínimo duas vezes inferior ao número de pessoas que usam outra forma de esgotamento sanitário (e.g. fossa séptica, fossa rudimentar e vala).
As cabeceiras dos rios do Mudo e Guajiru, alvo deste estudo, estão submetidas ao regime climático “As" - Clima Tropical chuvoso com verão seco (Kottek et al., 2006). A média de chuva anual (700 $\mathrm{mm} / \mathrm{ano})$ é semelhante à de regiões do semiárido (Alvares et al.,2013). Tipicamente a região semiárida do Nordeste, encontra-se sob estresse hídrico. No entanto nos últimos anos este quadro vem se agravando devido a um período de estiagem atípico, que se arrasta desde 2012 (Marengo e Bernasconi, 2015; Marengo et al., 2016).

Na Lagoa de Extremoz e no Rio Doce (figura 01), já foram apontados problemas de contaminação por metais (Barbosa et al., 2010; Azevedo Filho et al., 2012; Nóbrega, 2015; Nóbrega et al. 2017 Gomes et al., 2016a; Gomes et al., 2016b). Segundo Melo et al. (2012) as atividades humanas são as principais responsáveis pelo enriquecimento dos metais. Nóbrega, (2015) aponta para o aumento dos riscos de contaminação de metais em áreas pontuais da Lagoa, que foi acentuado durante os períodos chuvosos. No Rio Doce há risco de contaminação por pesticidas, devido ao uso indiscriminado destas substâncias no cultivo de hortaliças (Moura et al., 2013). Atualmente observa-se um movimento de ocupação humana em direção as partes mais interioranas, em poucos anos acredita-se que os mesmos fatores de impacto ambientais presentes no médio e baixo curso atualmente, atinjam as áreas de nascentes.

Os metais são considerados um dos principais

Figura 1 - Bacia do rio Doce, estações de amostragem M1, M2, M3, M4, G1, G2, G3 e G4.

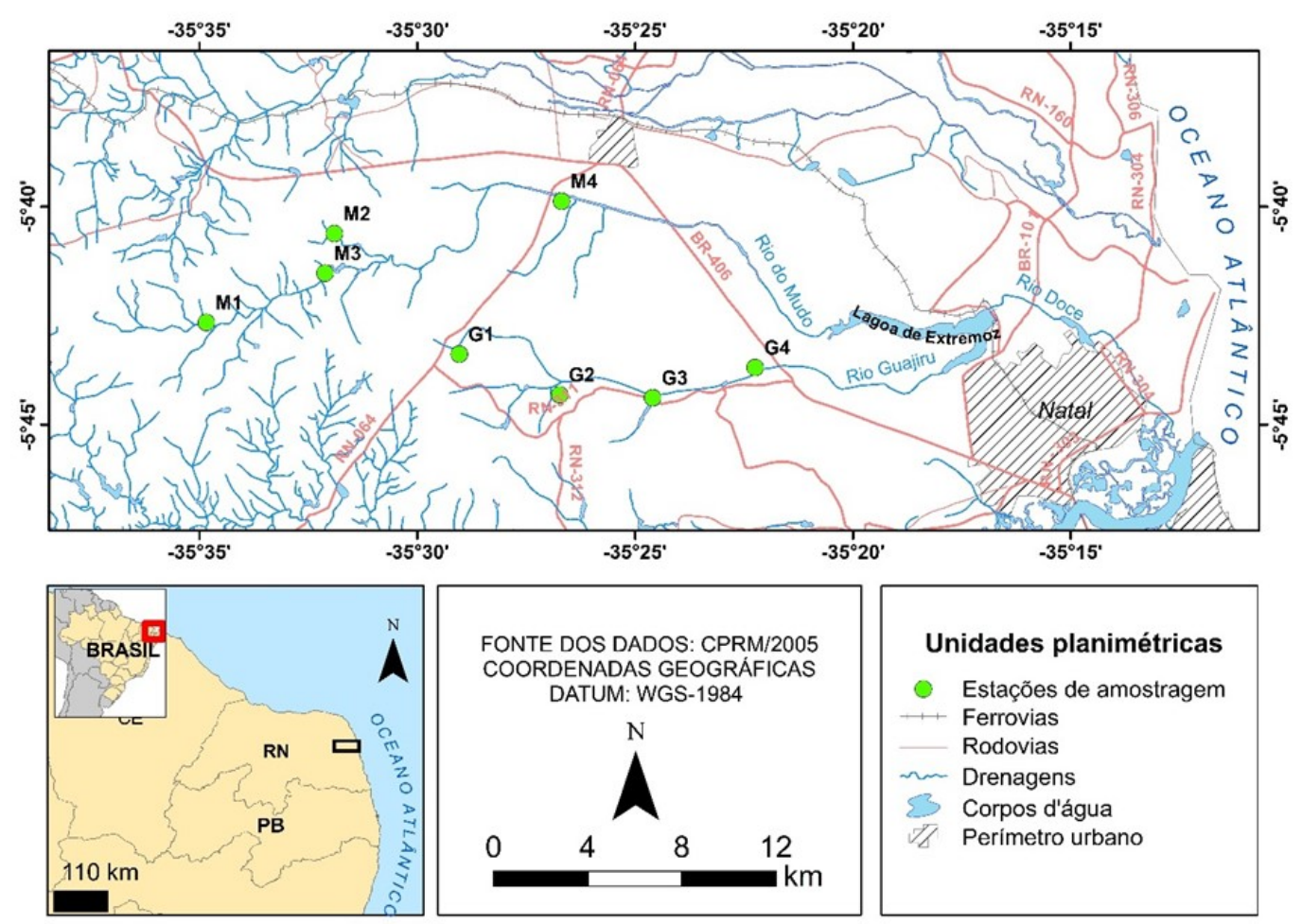


poluentes do ecossistema aquático, seus efeitos deletérios à cladóceras são discutidos amplamente na literatura (e.g. Zou e Bu, 1994; Sofyan et al., 2007; Naddy et al. 2015). Uma das fontes geogênicas de metais nos ecossistemas é o desgaste das rochas, que ocorre naturalmente como efeito dos diversos tipos de intemperismo (Forstner e Wittmann, 1981; Davis et al., 2003). Ainda segundo estes autores, as atividades humanas são outra fonte de metais, chamadas de fontes antrópicas. Metais como $\mathrm{Zn}$ e $\mathrm{Cu}$ quando enriquecidos na água superficial de reservatórios de zona rural, são principalmente originados do uso de fertilizantes e escoamento de efluentes domésticos (Aprile e Bouvy, 2010; Alves et al., 2014). O incremento de metais está diretamente associado com a maioria dos impactos deletérios à biota e seu potencial toxicológico pode ser influenciado por diversas variáveis, tais como dureza, pH e até a ação conjunta dos metais (Belanger et al., 1989; Welsh et al., 2000; Hyne et al., 2005; Cooper et al., 2009; CCME, 2008, 2014)

As espécies usadas no presente trabalho foram Ceriodaphnia dubia, C. silvestrii e Moina micrura. A primeira é típica de regiões temperadas (América do Norte e Europa), a segunda tem ocorrência no Brasil (Rio Grande do sul, Goiás e Distrito Federal) (Elmoor-Loureiro, 1997). O uso de C. dubia e C. silvestrii em ensaios ecotoxicológicos é comum (e.g. Belanger et al., 1989; Hyne et al., 2005; Cooper et al., 2009; Naddy et al., 2015; Nóbrega et al., 2017). Na região estudada, Gomes et al. (2016a) e Gomes et al. (2016b), realizaram ensaios ecotoxicológicos em água do Rio Doce utilizando C. dubia e C. silvestrii como organismos teste. A Moina micrura pode ser encontrada em pequenos reservatórios da região nordeste (Soares et al., 2011 e Diniz et al., 2013;); estes reservatórios têm características ambientais e sociais comuns às encontradas nos reservatórios das sub-bacias do Rio do Mudo e do Rio Guajiru. Em relação aos outros cladóceras, a M. micrura é pouco aproveitada como organismo teste (e.g. Ferrão-Filho et al., 2009).

O objetivo geral deste trabalho foi avaliar a qualidade da água superficial, através de análises químicas, físicas e ecotoxicológicas, com espécies de cladóceras nativos e exóticos, em água de pequenos mananciais superficiais e de exsudações naturais na BHRD, nordeste do Brasil. Estes corpos d'água superficial encontram-se na porção oeste da BHRD e estão localizados nas sub-bacias dos Rios do Mudo e Guajiru, drenagens intermitentes localizadas entre a região semiárida e o litoral, sob os impactos de um dos períodos de estiagem mais severos dos últimos anos. Para esta avaliação, as características físicas, químicas e ecotoxicológicas foram relacionadas às informações sobre precipitação, ocupação do solo, critérios de qualidade para consumo humano, uso na irrigação, criação de animais e de proteção da vida aquática, de agências governamentais como Conselho Canadense de Ministros do Meio Ambiente (CCME), Organização Mundial da Saúde (WHO) e Organização das Nações Unidas para Agricultura e Alimentação (FAO).

\section{Metodologia}

\section{Descrição da área de estudo}

O estudo foi executado nas sub-bacias dos Rios do Mudo e Guajiru, bacia hidrográfica do Rio Doce (BHRD). Para efeito de análise, foi realizado um recorte espacial na BHRD (FIGURA 1). Estes dois corpos hídricos correm em sentido oeste-leste até convergirem, na altura do município de Extremoz, e formar a Lagoa de Extremoz, maior reservatório da bacia. Na porção mais interna ao continente a bacia apresenta características ambientais próximo ao que é observado no semiárido, enquanto a área leste apresenta características litorâneas. Na região litorânea a precipitação anual é próxima de 1400 $\mathrm{mm}$, enquanto nas áreas mais continentais, onde está localizada a área de estudo, a precipitação média é de $577 \mathrm{~mm}$ (Figura 2).

As estações de amostragem M1, M2 e M3, na sub-bacia do Rio do Mudo, são pequenos reservatórios de água, distribuídos ao longo da zona rural. Nestes locais a vegetação observada é esparsa, semelhante a vegetação típica da caatinga. A estação de amostragem M4 é um olheiro d'água às margens do Rio do Mudo. E na sub-bacia do rio Guajiru, nas proximidades da estação de amostragem G1 observou-se a predominância de áreas de cultivo. No entorno da estação de amostragem G2 verifica-se adensamento de residências; além disso a aproximadamente $500 \mathrm{~m}$ de distância deste ponto, existe uma instalação de beneficiamento de brita. A estação de amostragem G3 apresenta vegetação mais abundante e trata-se de um pequeno manancial margeado por uma estrada asfaltada. A estação de amostragem G4 é um olheiro, localizado no sopé de uma encosta.

\section{Coleta e Preparação das amostras.}

As coletas de água foram realizadas em agosto de 2016. Cada amostra de água era composta por uma mistura de alíquotas, coletadas espaçadamente cerca de $55 \mathrm{~cm}$ umas das outras, até completar a capacidade de dois recipientes cada um com volume de $2 \mathrm{~L}$. Um dos recipientes foi destinado para análise química e outro para os ensaios ecotoxicológicos. Os recipientes usados na coleta eram constituídos de material plástico com tampa, e foram previamente descontaminados. Todas as amostras foram acondicionadas em caixa térmica com gelo (exceto a amostra para OD), ou conservadas em geladeira até sua análise.

\section{Análises físicas e químicas da água}

As variáveis aferidas em água foram: $\mathrm{pH}$, condutividade elétrica (CE), turbidez, oxigênio dissolvido (OD), nitrogênio amoniacal (NA), dureza, cloreto, sílica e metais ( $\mathrm{Fe}, \mathrm{Cd}, \mathrm{Ni}, \mathrm{Cu}, \mathrm{Pb}, \mathrm{Zn}$ e $\mathrm{Cr}$ ). Todas as análises ocorreram em ambiente com temperatura controlada de $24^{\circ} \mathrm{C} \pm 1$. Para determinação de dureza $\left(\mathrm{mg} . \mathrm{L}^{-1} \mathrm{CaCO}_{3}\right)$, nitrogênio amoniacal $\left(\mathrm{NH}_{3}\right)$, oxigênio dissolvido em água $\left(\mathrm{mg} \cdot \mathrm{L}^{-1} \mathrm{O}_{2}\right)$, cloreto ( $\mathrm{mg} . \mathrm{L}^{-1} \mathrm{Cl}$ ) e sílica $\left(\mathrm{mg} . \mathrm{L}^{-1} \mathrm{SiO}_{2}\right)$ foram usados os 
métodos propostos CLESCERI et al. (1989). A abertura das amostras de água para dosagem de metais foi realizada usando solução mista $\left(\mathrm{HCl} 0,5 \mathrm{~N}+\mathrm{H}_{2} \mathrm{SO}_{4} 0,025 \mathrm{~N}\right)$; o teor de $\mathrm{Zn}, \mathrm{Cd}, \mathrm{Cr}, \mathrm{Fe}$, Ni e $\mathrm{Cu}$ foi medido em aparelho de espectrofotometria de absorção atômica de chama (EAA) modelo Varian Spectraa 220FS.

\section{Cultivo de cladóceras e ensaios ecotoxicológicos.}

Os organismos testes adultos foram mantidos em meio de cultura líquido, constituído por água natural coletada no reservatório superficial da escola agrícola de Jundiai (EAJ - 238717.87 mE e 9348414.94 mN), Macaíba. Este corpo hídrico possui características naturais e com pouca influência da ação antrópica. No laboratório a água foi filtrada em peneira de $45 \mu \mathrm{m}$ e permaneceu em aeração constante por no mínimo três horas antes de ser utilizada. No máximo 50 matrizes de cladocera foram mantidas em béqueres de 1L. Diariamente cada béquer recebeu $3 \mathrm{~mL}$ de extrato liquefeito de ração para peixe (Ração Tetram Min ${ }^{\circledR}$ Flakes ou AlconBasic ${ }^{\circledR}$ ) e $3 \mathrm{~mL}$ de cultura algal de Scenedesmus obliquus. Os neonatos foram retirados dos béqueres matrizes, para controle da idade dos organismos; semanalmente procedeu-se renovação e limpeza destes aquários.

Foram usados como indicadores de toxicidade de água superficial neonatos de C. dubia, C. silvestrii e $M$. micrura, com idades entre 6 e $12 \mathrm{~h}$. Estes organismos foram expostos, em frascos individuais, a $15 \mathrm{~mL}$ das amostras. $\mathrm{O}$ ensaio indicado para este tipo de análise consiste em teste crônico semi-estático com duração de 7 dias e 10 réplicas por tratamento. Neste método, ao completar 72h e 120 h de exposição, ocorreram renovações de água, contagem e remoção dos neonatos. Os organismos foram alimentados com uma gota de extrato liquefeito de ração para peixe (Ração TetraMin ${ }^{\circledR}$ Flakes) e uma gota de cultura algal de Scenedesmus obliquus. O alimento é fornecido no primeiro dia de teste e nas renovações. Durante o teste foi contabilizado o número total de filhotes por fêmea (Reprodução).

\section{Análise dos Dados}

Para verificar as interações entre os dados das análises da água superficial, foi usado o software RStudio ${ }^{\circledR}$ Versão Gratuita Desktop 1.0.153 (RStudio Team, 2016), segundo Crawley (2005). Para verificar se os dados apresentam normalidade e homocedasticidade foram usados respectivamente teste de Shapiro-Wilk e teste F. No teste de hipótese, levou-se em consideração que aceitar a Ho significa que não existe indícios que as médias das variáveis analisadas são diferentes e aceitar Hi significa que existem indícios significativos para rejeitar Ho. Quando os dados eram paramétricos foi usado teste $\mathrm{T}$ de student ou Levene; para não paramétricos, utilizou-se teste de Wilcoxon.

O coeficiente de correlação de postos de Spearman no software Statistic 7, foi usada para avaliar as correlações entre os valores obtidos das análises físicas, químicas e ecotoxicológicas de água superficial.
Para os dados ecotoxicológicos, precisou-se determinar as diferenças entre os resultados dos tratamentos em relação ao controle; para isso foi utilizado o software Toxstat 3.3 para determinar a toxicidade das amostras. Primeiro avaliou-se a normalidade e homocedasticidade dos dados, respectivamente por Teste do qui-quadrado (x2) e Teste de Barttlett. Caso estas condições fossem atendidas usava-se o método estatístico paramétrico de Dunnett, para analisar a diferença significativa entre o controle e cada amostra. Constatada diferença a amostra foi considerada tóxica; as amostras que se enquadraram neste grupo foram indicadas por um asterisco $\left(^{*}\right)$. Quando os dados observados nos ensaios ecotoxicológicos não atenderam os pressupostos de normalidade ou homocedasticidade, usou-se o teste de Steel Many-One; a amostra foi então considerada tóxica caso fosse significativamente diferente do controle, e indicada com o mesmo padrão descrito anteriormente (Zagatto e Bertoletti, 2014).

O fator de enriquecimento (FE) (Yongming et al., 2006), calculado a partir da formula (1), foi usado para avaliar o enriquecimento do metal no ambiente aquoso, a partir da classificação mostrada na tabela 1 , onde o número de asteriscos indica seu respectivo enriquecimento. Buscando determinar investigar a possível contaminação dos corpos hídricos por metais, usou-se o índice de contaminação (IC) adaptado de (Dauvalter e Rognerud, 2001) e exposto na formula (2). Valores de IC maiores que três, indicam contaminação severa foram marcados em negrito.

Onde:

$$
F E=\left(\frac{\left(\frac{C m}{C v r l}\right) \text { Amostra }}{\left(\frac{B m}{B v r l}\right) V R L}\right)
$$

Cm-Concentração de determinado elemento no local de interesse;

Cvrl-Concentração do elemento de referência no local de interesse:

Bm-Valor de referência do elemento de estudo (background);

Bvrl-Valor de referência local do elemento de referência (background).

Tabela 1 - Classificação do fator de enriquecimento (FE)

\begin{tabular}{l|c}
\hline \multirow{2}{*}{$F E<2$} & Classificação de Enriquecimento \\
\cline { 2 - 2 } & Deficiência de enriquecimento \\
\hline$F E=2-5$ & Enriquecimento moderado** \\
\hline$F E=5-20$ & Enriquecimento significativo** \\
\hline$F E=20-$ & Enriquecimento muito alto*** \\
40 & Enriquecimento extremamente alto*** \\
\hline$F E>40$ &
\end{tabular}

$$
I C=\left(\frac{C m}{B m}\right)
$$

Onde:

Cm-Concentração de determinado elemento no local de interesse;

Bm-Valor de referência do elemento de estudo (background). 
Para calcular o fator de enriquecimento (FE) e o índice de contaminação (IC), foram usados os valores de referência de cada microbacia, constituído pelos teores dos metais aferidos em M4 (microbacia do Rio do Mudo) e G4 (microbacia do rio Guajiru). Estes corpos hídricos são olheiros de água, o que diminui as chances de apresentarem concentrações alteradas pelas atividades humanas. O Ferro, foi usado como elemento de referência, pois dentre os metais analisados é o que apresenta menor mobilidade (Goldschmidt, 1937).

Para verificar a adequação dos resultados das análises aos possíveis usos da água, usou-se os critérios de qualidade de água canadense (Canadian Water Quality Guidelines- CWQG) para proteção da vida aquática (CCME, 2008; CCME, 2014), as diretrizes de qualidade de água potável da organização mundial da saúde (WHO, 2012) e os limites permitidos para uso na irrigação e criação de animais (Ayers e Westcot, 1994). No que diz respeito a proteção da vida aquática, foram usados como base, os critérios para água doce, são estes que apresentam características mais próximas aos corpos hídricos estudados.

\section{Resultados}

\section{Características físicas e químicas de água.}

$\mathrm{Na}$ tabela 3, foram expostos os valores e/ou teores máximos (em negrito) e mínimos (sublinhado) das variáveis: $\mathrm{pH}, \mathrm{CE}$, salinidade, turbidez, OD, NA, dureza, cloreto, sílica e metais ( $\mathrm{Fe}, \mathrm{Cd}, \mathrm{Zn}, \mathrm{Cr}, \mathrm{Pb}, \mathrm{Ni}$ e $\mathrm{Cu}$ ), assim como o valor médio e o desvio padrão destas variáveis, para cada grupo de amostras, aquelas coletadas no Rio do Mudo (M1, M2, M3 e M4) e no rio Guajiru (G1, G2, G3, G4).

Com exceção do OD $\left(8,17 \mathrm{mg} \cdot \mathrm{L}^{-1} \mathrm{O}_{2}\right)$ e do $\mathrm{Cu}(0,060$ mg. $L^{-1}$ ), na estação de amostragem $G 4$, as outras variáveis apresentaram valores máximos em corpos hídricos localizados na microbacia do Rio do Mudo. A estação de amostragem $\mathrm{M} 2$, apresentou os maiores valores para $\mathrm{CE}$ $\left(27.730,0 \mu \mathrm{S} . \mathrm{cm}^{-1}\right)$, NA $\left(4,91 \mathrm{mg} . \mathrm{L}^{-1} \mathrm{NH}_{3}\right)$, dureza $(4890,35$ mg. $\left.\mathrm{L}^{-1} \mathrm{CaCO}_{3}\right)$, cloreto $\left(10248,11 \mathrm{mg} \cdot \mathrm{L}^{-1}\right), \mathrm{Cd}\left(0,037 \mathrm{mg} . \mathrm{L}^{-}\right.$ 1), $\mathrm{Ni}\left(0,103 \mathrm{mg} \cdot \mathrm{L}^{-1}\right), \mathrm{Pb}\left(0,327 \mathrm{mg} \cdot \mathrm{L}^{-1}\right)$ e $\mathrm{Zn}\left(0,080 \mathrm{mg} \cdot \mathrm{L}^{-1}\right)$, enquanto na estação $\mathrm{M} 1$, as variáveis com maiores valores e teores foram turbidez (25,55 Ut), sílica (50,00 mg. $\left.\mathrm{L}^{-1}\right), \mathrm{Fe}$ (1,960 mg. $\left.\mathrm{L}^{-1}\right)$ e Cd $\left(0,037 \mathrm{mg} . \mathrm{L}^{-1}\right)$; a estação $\mathrm{M} 3$ apresentou $\mathrm{pH} 8,7$, maior valor dentre as outras amostragens.

Os valores mínimos das variáveis foram respectivamente: $\mathrm{pH}(6,8)$ nas estações M2 e G4; CE $\left(71,6 \mu \mathrm{S} . \mathrm{cm}^{-1}\right)$ em G4; turbidez (0.5 Ut) em G1; OD (1,18 mg.L-1 O2) em M1; NA (0,06 mg.L-1 NH3) em G3; dureza (4,16 Mg.L. $\mathrm{L}^{-1}$ $\mathrm{CaCO}_{3}$ ) em $\mathrm{G} 4$; cloreto $\left(19,33 \mathrm{mg} \cdot \mathrm{L}^{-1}\right)$; sílica $\left(3,79 \mathrm{mg} \cdot \mathrm{L}^{-1}\right)$ em G1; Fe $\left(0,05\right.$ mg. $\left.L^{-1}\right)$ em M4; Cd $\left(0,003\right.$ mg. $\left.L^{-1}\right)$ em G1, G2, G3 e G4; Ni (0,103 mg.L-1) em G1; Cu $\left(0,007 \mathrm{mg} \cdot \mathrm{L}^{-1}\right)$ em G1; Pb (0,040 mg. $\left.\mathrm{L}^{-1}\right)$ em G4; Zn $\left(0,040\right.$ mg. $\left.\mathrm{L}^{-1}\right)$ em G4; em nenhuma das amostras as concentrações de $\mathrm{Cr}$, foram suficientes para serem detectadas.

Embora estes pequenos reservatórios e olheiros, estejam sob condições sociais e ambientais aparentemente semelhantes, foi verificado que os valores numéricos das variáveis $\mathrm{CE}$, dureza, $\mathrm{Cd}, \mathrm{Ni}$, cloreto, aferidos nas estações de amostragem nos corpos de água superficial localizados na sub-bacia do Rio do Mudo apresentaram diferenças significativas $(\mathrm{p}<0,05)$, daquelas aferidas nos reservatórios e olheiro d'água distribuídos na sub-bacia do rio Guajiru.

\section{Ensaios ecotoxicológicos}

A figura 2 apresenta o número de organismos, das espécies C. dubia, C. silvestrii e M. micrura, que apresentavam mobilidade no final dos ensaios ecotoxicológicos; aquelas amostras que apresentaram diferenças significativas em relação ao controle foram consideradas tóxicas e marcadas com um asterisco (*). Nas amostras M1, M2 e M3, não foi detectada mobilidade dos organismos expostos. Este comportamento já era esperado devido a CE das amostras, que foram respectivamente 25230,0 $\mu \mathrm{S} . \mathrm{cm}^{-1}, 27730,0 \mu \mathrm{S} . \mathrm{cm}^{-1}$ e $10720,0 \mu \mathrm{S} . \mathrm{cm}^{-1}$, o que indicam um ambiente salino.

As proporções de filhotes por fêmeas, variável referente a capacidade de reprodução dos organismos testes, são apresentadas na figura 3 e as amostras tóxicas são indicadas com um asterisco $\left(^{*}\right)$. Nas amostras M1, M2 e M3 não foi possível determinar efeito tóxico à reprodução nos organismos teste, pois foi observado efeito tóxico agudo sobre todos os organismos expostos. Dentre as amostras M4, G1, G2, G3 e G4, nenhuma apresentou efeito tóxico crônico à reprodução de C. dubia. Nas amostras G3 e G4 foi observado efeito tóxico crônico sobre a reprodução de C. silvestrii, enquanto que G1 e G3 apresentaram efeito tóxico crônico sobre a reprodução de M. micrura.

Os dados apontam para maior similaridade dos resultados, quando foi analisada a variável mobilidade, pois ao comparar a média de observações de organismos moveis de cada espécie, tanto a partir de observações da figura 2 , quanto pelo teste de Wilcoxon, não existiam indícios significativos para refutar $\mathrm{Ho}$ (médias dos resultados obtidos nos tratamentos são iguais). Este comportamento é semelhante ao observado na comparação dos valores das variáveis físicas e químicas das estações de amostragem na sub-bacia do Rio do Mudo, em relação as estações de amostragem ao longo do rio Guajiru. Isto corrobora com a hipótese alternativa $(\mathrm{Hi})$, de que as águas superficiais das duas sub-bacias apresentam características diferentes no período estudado.

$\mathrm{Na}$ tabela 4 foram expostos os coeficientes de correlação de Spearman entre as variáveis químicas e ecotoxicológicas analisadas nas amostras de água superficial e dos olheiros. Esta matriz de correlação permite verificar as interações entre os valores das variáveis estudadas e determinar padrões de comportamento dos dados. As correlações marcadas em vermelho são aquelas significativas $(\mathrm{p}<0,05)$. Estas correlações podem ser classificadas como positivas e negativas. As correlações positivas indicam que quando uma variável apresenta tendência de valores crescentes, por exemplo, a outra apresenta a mesma tendência. Os valores negativos indicam tendências opostas.

As variáveis de mobilidade (CDm, CSm e $\mathrm{MMm}$ ) correlacionam-se positivamente, ou seja, o número de orga- 
Tabela 3 - Variáveis pH, condutividade elétrica (CE), turbidez, oxigênio dissolvido (OD), nitrogênio amoniacal (NA), dureza, cloreto, sílica, $\mathrm{Fe}, \mathrm{Cd}, \mathrm{Ni}, \mathrm{Cu}, \mathrm{Pb}, \mathrm{Zn}$ e Cr aferidos em amostras de água superficial de reservatórios nas sub-bacias dos Rios do Mudo e Guajiru.

\begin{tabular}{|c|c|c|c|c|c|c|c|c|c|}
\hline & & $\mathrm{pH}$ & CE & Turbidez & OD & NA & Dureza & Cloreto & Sílica \\
\hline & & & $\mu \mathrm{S} . \mathrm{cm}^{-1}$ & Ut & \multicolumn{5}{|c|}{$m g . L^{-1}$} \\
\hline \multirow{4}{*}{$\begin{array}{l}\text { Rio do } \\
\text { Mudo }\end{array}$} & M1 & 7,4 & 25230,0 & 25,55 & 1,18 & 2,01 & 4370,10 & 8959,04 & 50,00 \\
\hline & $\mathrm{M} 2$ & $\underline{6,8}$ & 27730,0 & 4,00 & 5,12 & 4,91 & 4890,35 & 10248,11 & 9,82 \\
\hline & M3 & 8,7 & 10720,0 & 15,55 & 4,92 & 0,61 & 1529,53 & 3577,17 & 39,71 \\
\hline & M4 & 7,7 & 928,0 & 0,10 & 4,92 & 0,02 & 228,91 & 186,92 & 28,43 \\
\hline \multicolumn{2}{|c|}{ Média } & 7,6 & 16152,0 & 11,300 & 4,035 & 1,888 & 2754,723 & 5742,810 & 31,990 \\
\hline \multicolumn{2}{|c|}{ DP } & 0,794 & 12619,257 & 11,545 & 1,906 & 2,181 & 2239,879 & 4697,509 & 17,206 \\
\hline \multirow{4}{*}{$\begin{array}{c}\text { Rio } \\
\text { Guajiru }\end{array}$} & G1 & 8,0 & 822,1 & $\underline{0,50}$ & 6,00 & 0,28 & 67,63 & 180,47 & 3,79 \\
\hline & G2 & 8,7 & 828,4 & 14,44 & 3,74 & 0,33 & 83,24 & 174,02 & ALD \\
\hline & G3 & 8,3 & 1863,6 & 2,83 & 6,70 & $\underline{0,06}$ & 270,53 & 499,52 & 22,34 \\
\hline & G4 & $\underline{6,8}$ & $\underline{71,6}$ & 1,71 & 8,17 & ALD & 4,16 & 19,33 & 13,54 \\
\hline \multicolumn{2}{|c|}{ Média } & 7,9 & 896,4 & 4,87 & 6,153 & 0,223 & 106,390 & 218,335 & 13,223 \\
\hline \multicolumn{2}{|c|}{ DP } & 0,819 & 736,191 & 6,451 & 1,845 & 0,144 & 114,646 & 201,714 & 9,279 \\
\hline
\end{tabular}

CE: Condutividade elétrica; OD: Oxigênio dissolvido; NA: Nitrogênio amoniacal; DP = Desvio padrão, ALD= Abaixo do limite de detecção, $\mathrm{ND}=$ Não determinado. Em negrito, os valores máximos e sublinhados os valores mínimos.

Tabela 3 - Continuação...

\begin{tabular}{|c|c|c|c|c|c|c|c|c|}
\hline & & $\mathrm{Fe}$ & $\mathrm{Cd}$ & $\mathrm{Ni}$ & $\mathrm{Cu}$ & $\mathrm{Pb}$ & $\mathrm{Zn}$ & $\mathrm{Cr}$ \\
\hline & \multicolumn{8}{|c|}{$m g \cdot \mathrm{L}^{-1}$} \\
\hline \multirow{4}{*}{$\begin{array}{l}\text { Rio do } \\
\text { Mudo }\end{array}$} & M1 & 1,960 & 0,037 & 0,093 & 0,050 & 0,330 & 0,073 & ALD \\
\hline & M2 & 0,410 & 0,037 & 0,103 & 0,050 & 0,327 & 0,080 & ALD \\
\hline & M3 & 0,660 & 0,017 & 0,047 & 0,027 & 0,217 & 0,060 & ALD \\
\hline & M4 & 0,050 & 0,007 & 0,057 & 0,027 & 0,060 & 0,060 & ALD \\
\hline \multicolumn{2}{|c|}{ Média } & 0,770 & 0,025 & 0,075 & 0,154 & 0,039 & 0,068 & ND \\
\hline \multicolumn{2}{|c|}{ DP } & 0,832 & 0,015 & 0,027 & 0,238 & 0,013 & 0,010 & $\mathrm{ND}$ \\
\hline \multirow{4}{*}{$\begin{array}{c}\text { Rio } \\
\text { Guajiru }\end{array}$} & G1 & 0,180 & $\underline{0,003}$ & $\underline{0,003}$ & $\underline{0,007}$ & 0,050 & 0,047 & ALD \\
\hline & G2 & 0,270 & 0.003 & 0,007 & 0,013 & 0,063 & 0,047 & ALD \\
\hline & G3 & 0,310 & 0,003 & ALD & 0,060 & 0,050 & 0,053 & ALD \\
\hline & G4 & 0,150 & 0,003 & 0,010 & 0,020 & $\underline{0,040}$ & 0,040 & ALD \\
\hline \multicolumn{2}{|c|}{ Média } & 0,228 & 0,003 & 0,007 & 0,025 & 0,051 & 0,047 & ND \\
\hline \multicolumn{2}{|c|}{ DP } & 0,075 & 0,000 & 0,004 & 0,024 & 0,009 & 0,005 & $\mathrm{ND}$ \\
\hline
\end{tabular}

CE: Condutividade elétrica; OD: Oxigênio dissolvido; NA: Nitrogênio amoniacal; DP = Desvio padrão, ALD= Abaixo do limite de deteç̧ão, ND = Não determinado. Em negrito, os valores máximos e sublinhados os valores mínimos.

Figura 2 - Número de organismos com mobilidade, por estação de amostragem, para cada espécie, nos ensaios ecotoxicológicos com cladóceras. Amostras tóxicas $(p<0,05)$ marcadas com asterisco $(*)$.

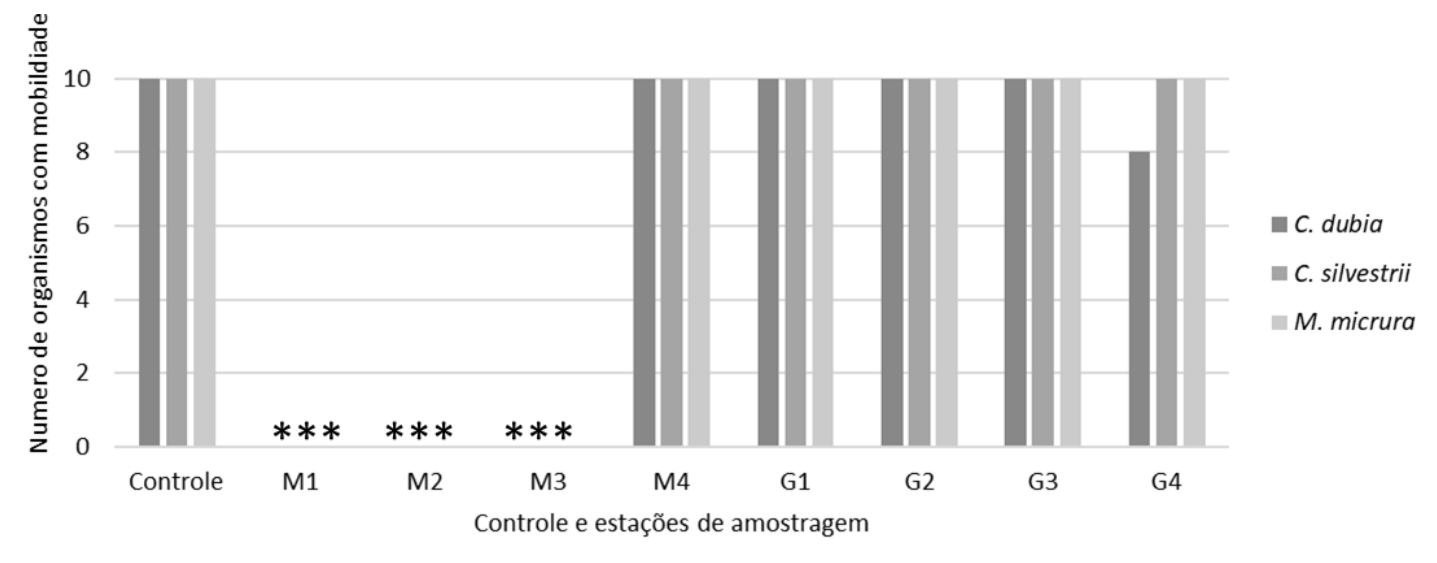


Figura 3 - Proporção de filhotes por fêmeas, por estação de amostragem, para cada espécie, nos ensaios ecotoxicológicos com cladóceras. Amostras tóxicas $(p<0,05)$ marcadas com asterisco $\left({ }^{*}\right)$.

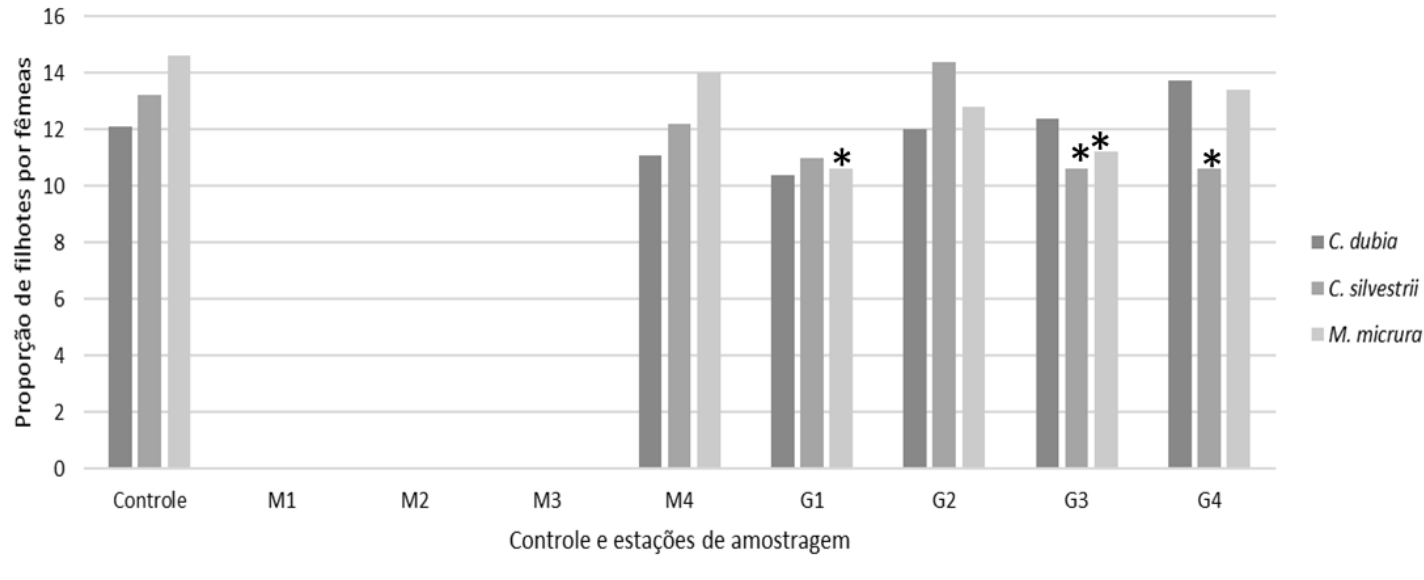

Tabela 4 - Coeficiente de correlação de postos de Spearman, entre as variáveis ecotoxicológicas, físicas e químicas aferidas nas amostras de água superficial e de olheiros nas sub-bacias dos rios do Mudo e Guajiru.

\begin{tabular}{l|l|l|l|l|l|l|l|l|l|l|}
\hline & CDm & CDr & CSm & CSr & MMm & MMr & pH & CE & Turb & OD \\
\hline $\mathrm{CDm}$ & 1,00 & & & & & & & & & \\
\hline $\mathrm{CDr}$ & 0,67 & 1,00 & & & & & & & & \\
\hline $\mathrm{CSm}$ & 0,93 & 0,87 & 1,00 & & & & & & & \\
\hline $\mathrm{CSr}$ & 0,91 & 0,62 & 0,87 & 1,00 & & & & & & \\
\hline $\mathrm{MMm}$ & 0,93 & 0,87 & 1,00 & 0,87 & 1,00 & & & & & \\
\hline $\mathrm{MMr}$ & 0,73 & 0,83 & 0,87 & 0,81 & 0,87 & 1,00 & & & & \\
\hline $\mathrm{pH}$ & 0,38 & 0,02 & 0,17 & 0,34 & 0,17 & $-0,01$ & 1,00 & & & \\
\hline $\mathrm{CE}$ & $-0,65$ & $-0,76$ & $-0,85$ & $-0,71$ & $-0,85$ & $-0,73$ & $-0,10$ & 1,00 & & \\
\hline Turb & $-0,67$ & $-0,51$ & $-0,73$ & $-0,58$ & $-0,73$ & $-0,71$ & 0,23 & 0,60 & 1,00 & \\
\hline $\mathrm{OD}$ & 0,24 & 0,58 & 0,45 & 0,02 & 0,45 & 0,29 & $-0,30$ & $-0,46$ & $-0,60$ & 1,00 \\
\hline $\mathrm{NA}$ & $-0,65$ & $-0,85$ & $-0,85$ & $-0,59$ & $-0,85$ & $-0,88$ & 0,02 & 0,81 & 0,74 & $-0,57$ \\
\hline $\mathrm{Dur}$ & $-0,65$ & $-0,76$ & $-0,85$ & $-0,71$ & $-0,85$ & $-0,73$ & $-0,10$ & 1,00 & 0,60 & $-0,46$ \\
\hline $\mathrm{Clor}$ & $-0,65$ & $-0,81$ & $-0,85$ & $-0,76$ & $-0,85$ & $-0,78$ & $-0,16$ & 0,98 & 0,50 & $-0,36$ \\
\hline $\mathrm{Si} \mathbf{l i c a}$ & $-0,50$ & $-0,37$ & $-0,51$ & $-0,58$ & $-0,51$ & $-0,27$ & $-0,08$ & 0,48 & 0,33 & $-0,30$ \\
\hline $\mathrm{Fe}$ & $-0,72$ & $-0,68$ & $-0,85$ & $-0,77$ & $-0,85$ & $-0,90$ & 0,13 & 0,79 & 0,90 & $-0,46$ \\
\hline $\mathrm{Cd}$ & $-0,80$ & $-0,85$ & $-0,91$ & $-0,72$ & $-0,91$ & $-0,65$ & $-0,34$ & 0,87 & 0,51 & $-0,54$ \\
\hline $\mathrm{Ni}$ & $-0,73$ & $-0,66$ & $-0,73$ & $-0,53$ & $-0,73$ & $-0,37$ & $-0,55$ & 0,64 & 0,31 & $-0,47$ \\
\hline $\mathrm{Cu}$ & $-0,49$ & $-0,33$ & $-0,57$ & $-0,65$ & $-0,57$ & $-0,42$ & $-0,26$ & 0,79 & 0,46 & $-0,23$ \\
\hline $\mathrm{Pb}$ & $-0,66$ & $-0,85$ & $-0,85$ & $-0,52$ & $-0,85$ & $-0,70$ & 0,00 & 0,85 & 0,74 & $-0,81$ \\
\hline $\mathrm{Zn}$ & $-0,60$ & $-0,80$ & $-0,80$ & $-0,62$ & $-0,80$ & $-0,62$ & $-0,22$ & 0,95 & 0,41 & $-0,50$ \\
\hline
\end{tabular}

CDm: C. dubia mobilidade; CDr: C. dubia reprodução; CSm: C. silvestrii mobilidade; CSr: C. silvestrii reprodução; MMm: M. micrura mobilidade; MMr: M. micrura reprodução; CE: Condutividade elétrica; Turb: Turbidez; OD: Oxigênio dissolvido; NA: Nitrogênio amoniacal; Dur: Dureza e Clor: Cloreto. Coeficientes de correlação marcados por negrito são significativos para $\mathrm{p}<0,05$

Tabela 4 - Continuação...

\begin{tabular}{|c|c|c|c|c|c|c|c|c|c|c|}
\hline \multirow{2}{*}{\multicolumn{11}{|c|}{$\mathrm{CDm}$}} \\
\hline & & & & & & & & & & \\
\hline CDr & & & & & & & & & & \\
\hline CSm & & & & & & & & & & \\
\hline $\begin{array}{l}\text { CSr } \\
\text { MMr }\end{array}$ & & & & & & & & & & \\
\hline $\begin{array}{l}\text { MIVIn } \\
\text { MMr }\end{array}$ & & & & & & & & & & \\
\hline $\mathrm{pH}$ & & & & & & & & & & \\
\hline CE & & & & & & & & & & \\
\hline $\begin{array}{c}\text { urb } \\
O D\end{array}$ & & & & & & & & 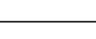 & & \\
\hline NA & 1.00 & & & & & & & & & \\
\hline Dur & 0.81 & 1.00 & & & & & & & & \\
\hline Clor & 0.79 & 0.98 & 1.00 & & & & & & & \\
\hline Sílica & 0.10 & 0.48 & 0.50 & 1.00 & & & & & & \\
\hline $\mathrm{Fe}$ & 0,83 & 0,79 & 0.76 & 0.43 & 1.00 & & & & & \\
\hline $\mathrm{Cd}$ & 0.74 & 0.87 & 0.87 & 0.57 & 0,64 & 100 & & & & \\
\hline $\mathrm{Ni}$ & 0,55 & 0,64 & 0,62 & 0,40 & 0,33 & 0,91 & 1.00 & & & \\
\hline $\mathrm{Cu}$ & 0,38 & 0,79 & 0.77 & 0,71 & 0,62 & 0,64 & 0.44 & 1.00 & & \\
\hline $\mathrm{Pb}$ & 0,90 & 0,85 & 0,79 & 0,37 & 0,77 & 0,87 & 0,73 & 0,53 & 1,00 & \\
\hline $\mathrm{Zn}$ & 0,73 & 0.95 & 0,95 & 0.51 & 0.61 & 0.93 & 0.77 & 0.73 & 0.84 & 1.00 \\
\hline
\end{tabular}

CDm: $C$. dubia mobilidade; $\mathrm{CDr}$ C dubia reprodução; $\mathrm{CSm}$ : $C$ silvestrii mobilidade; $C \mathrm{Cr}$ : $C$. silvestrii reproducão; MMm: $M$ micrur mobilidade; MMr: M. micrura reprodução; CE: Condutividade elétrica; Turb: Turbidez; OD: Oxigênio dissolvido; NA: Nitrogênio amoniacal; Dur: Dureza e Clor: Cloreto. Coeficientes de correlação marcados por negrito são significativos para $\mathrm{p}<0,05$ 
Tabela 5- Índice de contaminação e fator de enriquecimento dos metais, Fe, Cd, Ni, Cu, Pb e Zn, aferidos nas estações de amostragem M1, M2, M3, G1, G2 e G3.

\begin{tabular}{c|c|c|c|c|c|c|c|c|c|c|c|c}
\hline & \multicolumn{2}{|c|}{ Fe } & \multicolumn{2}{c|}{ Cd } & \multicolumn{2}{c|}{ Ni } & \multicolumn{3}{c|}{ Cu } & \multicolumn{2}{|c|}{ Pb } & \multicolumn{2}{c}{ Zn } \\
\hline & IC & FE & IC & FE & IC & FE & IC & FE & IC & FE & IC & FE \\
\hline M1 & 39,20 & 1,00 & 5,29 & 0,13 & 1,63 & 0,31 & 18,89 & $11,58^{* *}$ & 5,50 & 0,29 & 1,22 & 0,22 \\
\hline M2 & 8,20 & 1,00 & 5,29 & 0,64 & 1,81 & 0,34 & 1,85 & 1,02 & 5,45 & $2,94^{*}$ & 1,33 & 0,24 \\
\hline M3 & 13,20 & 1,00 & 2,43 & 0,18 & 0,82 & 0,34 & 1,00 & 1,21 & 3,62 & $3,62^{*}$ & 1,00 & 0,28 \\
\hline G1 & 1,20 & 1,00 & 1,00 & 0,83 & 0,30 & 0,30 & 0,35 & 1,17 & 1,25 & $3,57^{*}$ & 1,18 & 0,94 \\
\hline G2 & 1,80 & 1,00 & 1,00 & 0,56 & 0,70 & 0,70 & 0,65 & 0,93 & 1,58 & $2,42^{*}$ & 1,18 & 0,75 \\
\hline G3 & 2,07 & 1,00 & 1,00 & 0,48 & 0,00 & 0,00 & 3,00 & ND & 1,25 & 0,42 & 1,33 & 1,06 \\
\hline
\end{tabular}

Os valores em negrito indicam que aquela amostra apresenta à contaminação severa do determinado metal. ND: Não determinado; enriquecimento moderado $\left({ }^{*}\right)$; enriquecimento significativo $\left(^{* *}\right)$; enriquecimento muito alto $\left({ }^{* * *}\right)$; enriquecimento extremamente alto $\left.{ }^{* * * *}\right)$

nismos que apresentaram mobilidade, nos ensaios com estas espécies, apresentam comportamento semelhante quanto ao seu aumento ou diminuição. Além disso, estes valores correlacionam-se negativamente com $\mathrm{Fe}, \mathrm{Cd}$ e $\mathrm{Ni}$, ou seja, quando o valor destes parâmetros aumenta, diminui o número de organismos móveis. As variáveis CSm e $\mathrm{MMm}$, além de se correlacionarem, também mostram correlação negativa com CE, turbidez, dureza, cloreto, $\mathrm{Pb}$ e $\mathrm{Zn}$. As variáveis CDr e CSr não se correlacionam significativamente; no entanto apresentam correlações similares com outras variáveis. Um exemplo disso são as correlações positivas com MMm e MMr, e negativas com dureza e cloreto. A variável CDr apresenta correlações negativas com CE, NA., Cd, Pb e Zn. CSr apresenta correlações negativas, além das já citadas, com os metais Fe e Cd. A variável MMr, além das correlações citadas anteriormente, apresentou correlações negativas com CE, NA, sílica e Fe.

Todas as correlações entre as variáveis físicas e químicas foram positivas. Dentre os metais observa-se a formação de três grupos a partir de suas correlações. $O$ primeiro por $\mathrm{Cd}, \mathrm{Ni}, \mathrm{Pb}$ e $\mathrm{Zn}$; o segundo por $\mathrm{Fe}$ e $\mathrm{Pb}$, e o último por $\mathrm{Cu}$ e $\mathrm{Zn}$. Dureza, condutividade elétrica e cloreto se correlacionam com os metais $\mathrm{Fe}, \mathrm{Cd}, \mathrm{Cu}$, $\mathrm{Pb}$ e $\mathrm{Zn}$. Os fatores de enriquecimento (FE) e índice de contaminação (IC) dos metais $\mathrm{Fe}, \mathrm{Cd}, \mathrm{Ni}, \mathrm{Cu}, \mathrm{Pb}$ e Zn, são apresentados na tabela 5 . Verificou-se a partir do IC (Em negrito: IC > 3 indica contaminação severa) contaminação em M1 (Fe, Cd, Cu e Pb), M2 (Fe, Cd e Pb) e M3 (Fe e Pb). Em M1 foi observado enriquecimento significativo de $\mathrm{Cu}$. Os teores de $\mathrm{Pb}$ encontravam-se enriquecidos significativamente nas estações de amostragem M2, M3, G1 e G2.

\section{Discussão}

No período estudado, verificou-se que devido a estiagem prolongado, as sub-bacias estavam submetidas a condições ambientais próximas àquelas verificadas em regiões quentes com clima semiárido (Figura 4). Regiões com clima semiárido são tipicamente formadas por reservatórios temporários, originados pela precipitação pluviométrica e sua manutenção também varia de acordo com a taxa de evaporação e infiltração no solo. Estas condições são responsáveis por mudanças flutuantes em suas características físicas e químicas. A região do semiárido brasileiro vivia no momento estudado um dos períodos de estiagem mais extenso e severo dos últimos 100 anos (Marengo e Bernasconi, 2015; Marengo et al., 2016).

Em períodos típicos no semiárido do nordeste brasileiro, espera-se uma precipitação média de $600 \mathrm{~mm}$ anuais (Marengo et al., 2011), segundo as informações obtidas a precipitação média anual em 2016 na área estudada foi 101,71 mm; neste mesmo período a precipitação média em um município do semiárido foi $49,32 \mathrm{~mm}$ e numa cidade do litoral 97,12 mm (IMET, 2018). Em relação a precipitação acumulada no ano, na área estudada foi observado $1220,6 \mathrm{~mm}$, enquanto que no semiárido 591,8 $\mathrm{mm}$ e no litoral $1165,4 \mathrm{~mm}$. Isto indica que a paisagem típica da área semiárida observada na área de estudo está provavelmente associada a outros fatores ambientais, além da precipitação.

No que diz respeito a ocupação do território e as atividades desenvolvidas na região, Faustino et al., (2014) mostrou a cobertura do solo na bacia estudada em 2011 (figura 5). Pode-se verificar que neste período predominavam campos antropizados, que por sua vez compreendiam: remanescentes de vegetação, vegetação esparsa e áreas de solos agricultáveis. Esta paisagem rural indica que era esperado que os teores de metais, provavelmente se devam principalmente a fatores ambientais, originando-se por exemplo, a partir do intemperismo das rochas (Forstner e Wittmann, 1981; Davis et al., 2003). Levando em consideração os cálculos do fator de enriquecimento, os metais Fe (em M1, M2 e M3), Cd (em M1 e M2), Cu (M1) e Pb (em M1, M2 e M3), apresentaram contaminação severa, enquanto que $\mathrm{Cu}$ apresentou enriquecimento significativo em $\mathrm{M} 1 \mathrm{e} \mathrm{Pb}$ exibiu enriquecimento moderado em M2, M3, G1 e G3. No entanto impactos resultantes de atividades humanas, neste caso a agricultura, não devem ter sua influência descartadas no comportamento dos metais. Pois embora em menor escala, o uso indiscriminado de insumos agrícolas pode contribuir para o aumento da concentração de alguns metais, e.g. Zinco e Cobre (Aprile e Bouvy, 2010; Alves et al., 2014).

Em comparação com os outros corpos hídricos da bacia, as condições são o oposto. Predomina na região 
Figura 4 - Precipitação mensal no ano de 2016, na área estudada, no semiárido e no litoral.

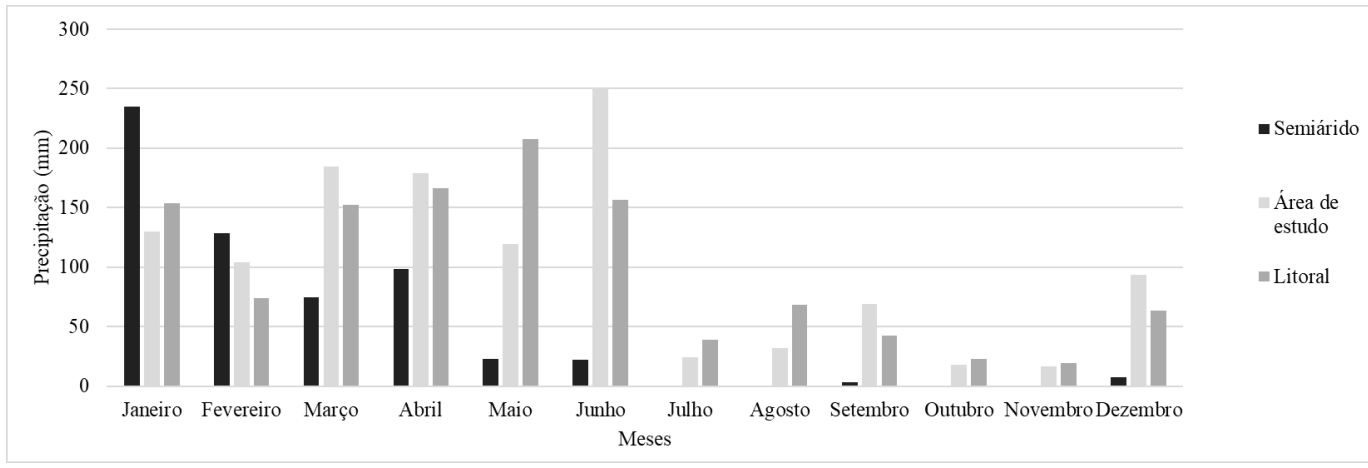

da lagoa de Extremoz e Rio Doce, o clima tropical chuvoso e características típicas de zonas urbanas e industriais. Estudos anteriores apontaram que a qualidade de água e sedimento superficial destes corpos hídricos, apresentam concentrações de metais superiores aos critérios de qualidade de água, adotados por órgãos de legislação ambiental, como o brasileiro CONAMA (Conselho Nacional do Meio Ambiente), o canadense CCME (Canadian Council of Ministers of the Environment) e o Norte Americano EPA (Envrionmental Protect Agency) (Barbosa et al., 2010; Azevedo Filho et al, 2012; Nobrega, 2015; Nobrega et al., 2017; Gomes et al., 2016a e Gomes et al., 2016b). Este comportamento se deve a dois processos, o da ocupação desordenada, que não foi acompanhada pela infraestrutura de saneamento (Melo et al., 2012) e o fato que por determinado período de tempo ocorreu uso indiscriminado de insumos agrícolas, que permanece em áreas próximas ao litoral, onde o cultivo de hortaliças é a principal fonte de renda dos residentes (Moura et al., 2013).

Segundo Esteves et al., 2011, a partir de análises do teor dos cátions $\mathrm{Ca}^{2+}, \mathrm{Mg}^{2+}, \mathrm{Na}^{+}, \mathrm{K}^{+}, \mathrm{Fe}^{3+}$ e $\mathrm{Mn}^{2+}$, e dos ânions $\mathrm{Cl}^{-}, \mathrm{SO}_{4}{ }^{2-}, \mathrm{CO}_{3}{ }^{2-}$ e $\mathrm{HCO}_{3}^{-}$, além de variáveis a eles associadas (e.g. pH, CE e dureza), é possível inferir sobre a influência geológica do regime de chuvas na área de drenagem e até mesmo sobre a proximidade de fontes poluidoras. Na sub-bacia do Rio do Mudo, verificou-se os maiores valores de CE (média 16152,0 $\mu \mathrm{S} . \mathrm{cm}^{-1}, \mathrm{n}=4$ ), em relação ao observado nas estações de amostragem do rio Guajiru (média 896,4 $\mu \mathrm{S} . \mathrm{cm}^{-1}, \mathrm{n}=4$ ). O mesmo foi observado para $\mathrm{Cl}^{-}$com teor médio de $5742,81 \mathrm{mg} \cdot \mathrm{L}^{-1}$ nos corpos hídricos do Rio do Mudo, enquanto que na sub-bacia do rio Guajiru verificou-se teor médio de $218.33 \mathrm{mg}$. $\mathrm{L}^{-1}$. Isto é um indicativo inicial de que embora geograficamente próximas, as sub-bacias em algum nível apresentam diferenças. Esta afirmação é suportada ao analisar-se os dados de Angelim (2006). Provavelmente as características químicas observadas nas águas dos pequenos mananciais do Rio do Mudo (M1, M2, M3 e M4), sejam resultado da influência do intemperismo das rochas que compõem o embasamento cristalino, enquanto que nos reservatórios do rio Guajiru (G1, G2, G3 e G4), predomina à influência de rochas sedimentares.

Ao avaliar a influência da precipitação e da capacidade de infiltração da água superficial no solo predominante da área, foi observado que os reservatórios do Rio do Mudo, apresentam características típicas do embasamento cristalino, predominante nesta sub-bacia, que dificulta a

Figura 5 - Mapa de Uso e Cobertura de solo na bacia do Rio Doce em 2011. Fonte: Faustino et al., (2014)

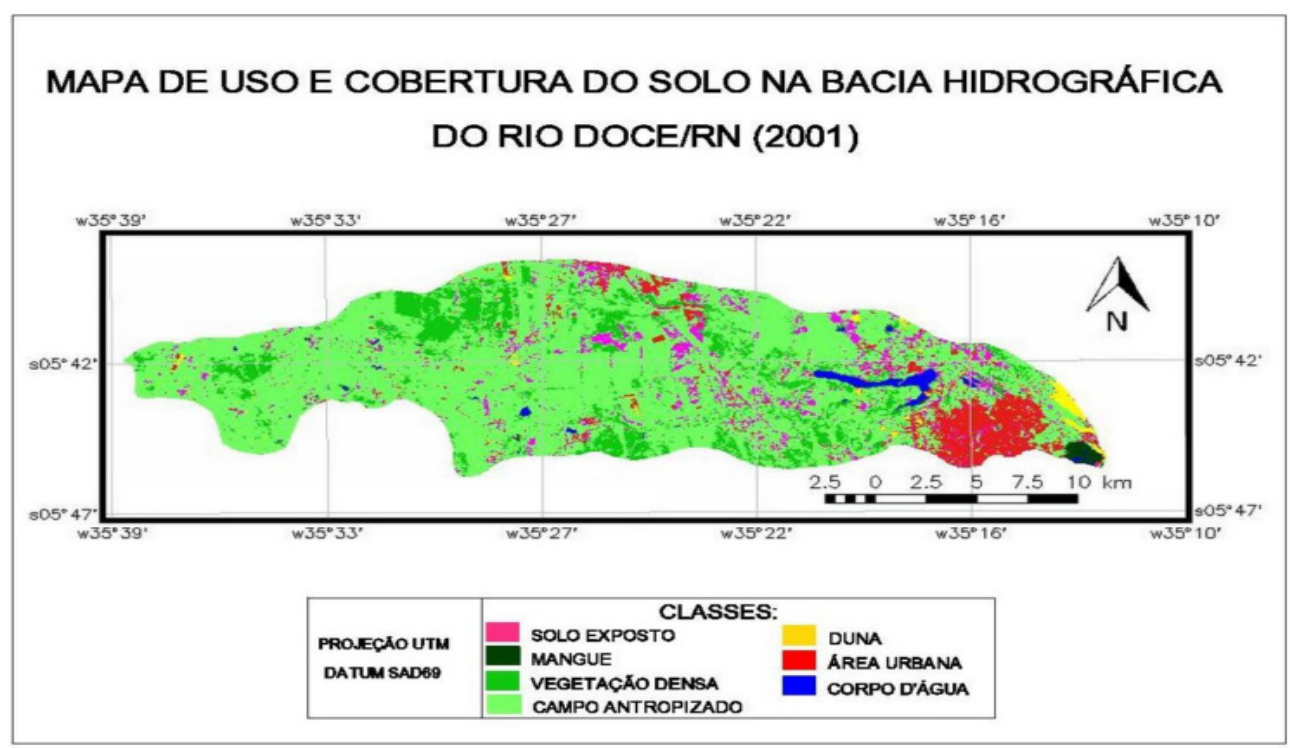


infiltração da água das chuvas; estas águas são represadas superficialmente, e estão sujeitas à maior evaporação, o que contribuiu para maior concentração dos cátions e ânions. Na área da sub-bacia do Rio Guajiru, provavelmente os reservatórios estudados, mesmo com índice de radiação solar alta, mantém seu volume por mais tempo. Isto acontece devido a recarga proveniente do aquífero, que se sustenta graças a maior capacidade de infiltração das rochas sedimentares. Desta forma o fator de diluição nestes corpos hídricos não foi afetado da mesma forma que aconteceu na sub-bacia do Rio do Mudo.

A Lei Federal 9.433, de janeiro de 1977, estabelece que em situações de escassez, o uso prioritário da água é o consumo humano e a dessedentação de animais, a partir disso foram feitas comparações para determinar se os corpos hídricos estudados se adequam as diretrizes de qualidade de água para tais usos. Como exposto até aqui, na área estuda predominava um período de estiagem iniciado em 2012, os meios de enfretamento da seca mais evidentes no momento das amostragens eram a captação da água das chuvas em cisternas ou abastecimento público de água. Isto significa que a maioria das pessoas desta região tinham assegurado, mesmo com limitações, água para necessidades básicas como higiene, preparação de alimento e consumo próprio. Assim foi considerado que o uso principal da água dos reservatórios estudados era a irrigação e dessedentação de animais de criação. Mesmo diante disto, não foi descartada a hipótese de que a população necessite recorrer aos reservatórios superficiais para conseguir água para consumo próprio. Diante disto, na tabela 6 pode ser observado se as variáveis analisadas se adequam às diretrizes proteção da vida aquática (CCME, 2008, 2014), potabilidade da água (WHO, 2012) e uso na para irrigação e criação de animais (Ayers e Westcot, 1994), o metal Cr não foi discutido pois em todas as amostras seu teor foi inferior ao limite de detecção da técnica usada.

Na estação de amostragem G3 o teor de Cd é inferior ao critério de qualidade para efeito tóxico agudo, em todas as outras observações os teores foram superiores as diretrizes, tanto para efeito tóxico agudo e tanto para efeito crônico. Para os outros metais verificou-se que os teores de $\mathrm{Pb}, \mathrm{Cu}$ e $\mathrm{Zn}$ foram maiores do que os limites de qualidade em todas as observações, os teores de Fe não se adequam aos critérios nas estações de amostragem M1, M2, M3 e G3. O Níquel e o Cromo foram os únicos elementos deste grupo que não apresentaram teores além dos critérios de qualidade. Outro indicio de que o teor destes elementos pode ter resultado em efeitos tóxicos, são as correlações negativas de seus valores com os resultados de sobrevivência e reprodução nos ensaios ecotoxicológicos (Tabela 4). Isto sugere que embora as amostras analisadas se tratem de misturas, os teores individuais dos elementos são suficientes para causar efeitos deletérios à sobrevivência e reprodução dos organismos teste. É importante ressaltar que a análise realizada aqui busca apontar o potencial ecotoxicológico das amostras, no entanto como se tratam de misturas, as amostras retratam infinitas possibilidades de interações químicas que podem ter influenciado nos resultados obtidos, desta forma indicar quais das variáveis são efetivamente tóxicas, é uma das limitações deste estudo, pois outros fatores podem ter influenciado no resultado dos ensaios, como por exemplo a dureza da amostra, as relações entre os metais em mistura, a variação de sensibilidade entre ordens taxonômicas e o tropismo dos metais por diferentes tecidos.

Ainda sobre os efeitos tóxicos à biota aquática, os resultados sugerem que os fatores que poderiam influenciar a composição química das amostras e consequentemente a toxicidade observada em M1, M2 e M3 (Figuras 2), estavam correlacionadas as variáveis ambientais limitantes, como é o caso da condutividade elétrica e cloreto. A partir da conversão da CE (CLESCERI et al., 1989), verificou-se que a salinidade em M1 foi 15,36 PSU, em M2 17,03 PSU e em M3 6,06 PSU; Hong et al., (2004) apontam que a concentração de efeito à $50 \%$ dos organismos expostos (EC50) ao NaCl, é 2.6 g.L.-1 $\left(1 \mathrm{PSU} \sim 1\right.$ g.L $\left.\mathrm{L}^{-1}\right)$ para $C$. cornuta, que corresponde a aproximadamente a $3,6 \%$ de salinidade, valor cerca de duas vezes menor do que foi aferido em M1, M2 e M3. Provavelmente nestas amostras a salinidade é um limitante ambiental à sobrevivência

Tabela 6 - Enquadramento das variáveis $\mathrm{Cd}, \mathrm{Ni}, \mathrm{Pb}, \mathrm{Cu}, \mathrm{Zn}, \mathrm{Fe} \mathrm{e} \mathrm{Cl}^{-}$

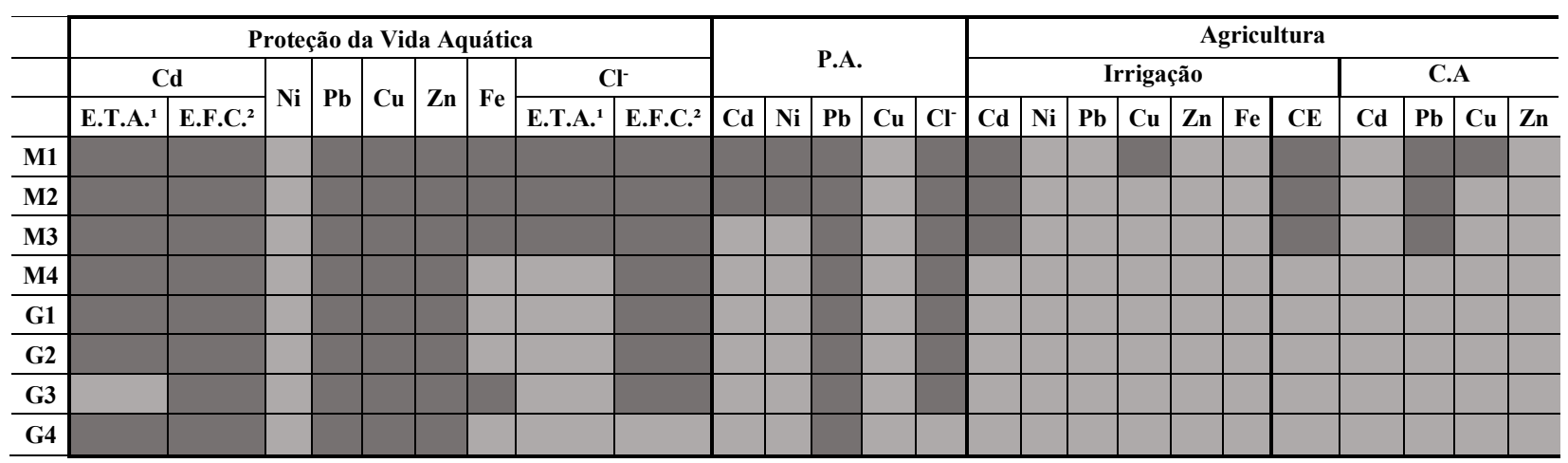

${ }^{1}$ Short-Term CQWG; ${ }^{2}$ Long-Term CQWG; E.T.A.: Efeito Tóxico Agudo; E.T.C.: Efeito Tóxico Crônico; CE: Condutividade Elétrica; C.A.: Criação de Animais. Em cinza escuro observações de valores superiores aos critérios de qualidade, em cinza claro valores inferiores aos critérios de qualidade. 
dos organismos. Deve-se considerar também que outros sais podem contribuir para a salinidade, além da $\mathrm{NaCl}$, o que pode implicar em diferentes efeitos tóxicos, como apontado por Zalizniak et al. (2006), neste estudo os autores verificaram que quando foram realizados ensaios tóxicos subletais, percebeu-se que sais compostos com maior proporção de $\mathrm{Ca}^{+2}$ eram menos nocivos.

A dureza da água é um parâmetro amplamente usado como modelo para calcular critérios de qualidade de água ambiental; isto ocorre pois em algumas situações os íons de $\mathrm{Ca}^{2+}$ e metais, competem por sítios de ligações. Exemplo disto foi mostrado em Hyne et al. (2005) que verificaram diminuição significativa da toxicidade de zinco com o aumento da dureza do meio. Padrão semelhante foi observado por Belanger et al. (1989), que mostraram que a toxicidade crônica de $\mathrm{Cu}$ à $\mathrm{C}$. dubia, é menor em águas com dureza maior. O efeito da dureza sobre a toxicidade também é observado para outros organismos, como é o caso dos peixes, como apontam Welsh et al. (2000) ao determinarem que a toxicidade de $\mathrm{Cu}$ à truta arco-íris (Oncorhynchus mykiss) e salmão chinook (O. tshawytscha), foi menor em águas com maior razão molar de $\mathrm{Ca}(\mathrm{Ca}: \mathrm{Mg})$; eles avaliaram ainda que quanto maior a concentração de $\mathrm{Ca}$, em relação ao $\mathrm{Mg}$, menor será a toxicidade.

Outro fator que influencia a toxicidade de uma amostra ambiental corresponde às interações entre os elementos estudados, pois nas amostras ambientais ocorre mistura de substâncias distintas em concentrações variadas (tabela 3). Na tentativa de exemplificar isto, Cooper et al. (2009) verificaram o efeito tóxico à $C$. dubia, a partir de uma mistura com 0,0109 mg. $\mathrm{L}^{-1} \mathrm{de} \mathrm{Cu}, 0,009 \mathrm{mg} \cdot \mathrm{L}^{-1} \mathrm{de} \mathrm{Pb}$ e $0,101 \mathrm{mg} \cdot \mathrm{L}^{-1}$ de $\mathrm{Zn}$, concentrações estas que atendem os critérios de qualidade de água, ou seja, isoladamente os metais nestas concentrações não causam mortalidade aos organismos expostos. Os autores constataram mortalidade de $65-100 \%$ dos organismos teste expostos a solução com a mistura de $\mathrm{Cu}, \mathrm{Pb}$ e $\mathrm{Zn}$.

Desta forma como já mencionado anteriormente considerou-se a alta complexidade das amostras ambientais, uma limitação deste estudo, pois foram analisadas tais como coletadas em campo, ou seja, sem correção de parâmetros como pH, dureza e CE. No entanto ao buscar aumentar a relevância deste estudo, foi considerado que a sensibilidade de espécies de cladóceras à metais parece variar entre as ordens taxonômicas, principalmente quando se compara espécies que ocorrem em habitats temperados e ou tropicais. No presente estudo foi verificado comportamento diferente entre os organismos estudados, este foi o caso da toxicidade na estação G1, verificada apenas para M. micrura, em G3 para C. silvestrii e M. micrura e G4 para C. silvestrii. Comportamentos como este, podem ser verificado ao analisar os estudos que avaliam a sensibilidade de cladóceras à metais e outras substâncias tal como Naddy et al. (2015), por exemplo, que ao avaliarem a toxicidade de $\mathrm{Cd}, \mathrm{Zn}$ e $\mathrm{Cu}$ à $C$. dubia, determinaram que o $\mathrm{Cd}$ foi mais tóxico que o $\mathrm{Cu}$ e Zn. Enquanto que Zou \& Bu (1994), usando Moina irrasa, obtiveram resultado diferente, neste caso, para as condições de teste empregadas o elemento mais tóxico é $\mathrm{Cu}$, seguido por $\mathrm{Cd}$ e $\mathrm{Zn}$.

Em relação aos teores de $\mathrm{Cl}^{-}$, a comparação entre aqueles aferidos nas estações de amostragem e as diretrizes de qualidade de água para efeito tóxico agudo e crônico de CCME (2008) sugeriam que nas amostras G1, G2, G3 e G4, deveria ser observado efeito tóxico agudo e crónico. No entanto esta condição só foi observada nas estações de amostragem G3 e G4 (para C. silvestrii) e G1 e G3 (para M. micrura). O resultado observado não é suficiente para confirmar que teores de cloreto superiores à $120 \mathrm{mg} \cdot \mathrm{L}^{-1}$ nas amostras de água foram os principais responsáveis pela toxicidade. É provável que isto se deva ao efeito protetivo da dureza (Elphick et al., 2011). As amostras G1, G3 e G4 apresentaram respectivamente 67,$63 ; 83,24$ e 4,16 mg. $\mathrm{L}^{-1} \mathrm{CaCO}_{3}$ de dureza em água, enquanto os teores de $\mathrm{Cl}^{-1}$ foram respectivamente 180,47; 499,52 e 19,33 mg. $\mathrm{L}^{-1}$. Isto está de acordo com os resultados de Elphick et al. (2011) que verificaram a toxicidade do cloreto à reprodução de C. dubia (IC50 - Concentração de Inibição à $50 \%$ dos organismos teste), em diferentes durezas de água. Os autores afirmaram que o IC50 $\mathrm{do}^{-}$diminuiu quando ocorreu o aumento de dureza. Neste caso a IC50 de $\mathrm{Cl}^{-}$para C. dubia em água com dureza 10, 20, 40, 80, 120 e $320 \mathrm{mg} \cdot \mathrm{L}^{-1} \mathrm{CaCO}_{3}$, foram respectivamente 161,301 , 481, 697.4, 895 e 700 mg. $\mathrm{L}^{-1}$ de $\mathrm{Cl}^{-}$.

Além destes íons, outras substâncias que ocorrem naturalmente nos reservatórios, podem infligir efeitos deletérios ao ecossistema aquático. As toxinas produzidas por cianobactérias, conhecidas por cianotoxinas, são comuns em vários reservatórios do nordeste do Brasil (Vilar et al., 2014; Borges et al., 2015) são um exemplo disso. Ao avaliar o efeito tóxico de florações de Microcystis sp sobre a mobilidade de M. minuta, Vilar et al. (2014) mostraram que, embora durante o período chuvoso e seco, a composição da floração seja semelhante, a toxicidade foi maior no período seco (Setembro/2012). Outro trabalho que mostra o potencial tóxico destas substâncias aos cladóceras, detectou efeito tóxico agudo à M. micrura, quando exposta a águas de um reservatório tropical no Rio de Janeiro, Brasil (Ferrão-Filho et al., 2009).

Em relação ao uso da água para consumo humano, considerou-se como mencionado anteriormente que o acesso à água potável nesta região é garantido até certo ponto. Assim não se pode descartar a possibilidade de a população residente eventualmente recorrer aos reservatórios estudados, para suprir suas necessidades fisiológicas. Diante disto e ao fato de não existirem plantas de tratamento de água na região, nesta pesquisa, a água foi analisada sem nenhum tipo de tratamento ou adição de condicionantes. Os resultados mostram que os teores de $\mathrm{Pb}$ em todas as observações foram superiores aos critérios de qualidade. Os teores de cloreto parecem seguir a mesma tendência pois apenas em G4 atende aos critérios de qualidade. Os teores de $\mathrm{Cd}$ e $\mathrm{Ni}$, não se adequam aos critérios de qualidade nas estações de amostragem M1 e M2.

A ingestão e a inalação são as principais formas de contaminação de humanos por $\mathrm{Pb}$, o sistema nervoso é principal alvo da a ação tóxica deste metal (ATSDR, 2007). Segundo Sisinno e Oliveira-Filho (2013) crianças de até 
6 anos possuem mais risco de envenenamento do que adultos e são mais sensíveis aos efeitos tóxicos, por não apresentarem a barreira hematoencefálica plenamente desenvolvida. As características socioeconômicas da população exposta também são impactadas pela contaminação por chumbo, o estudo conduzido por Hanna-Attisha et al., (2016) mostra que crianças mais pobres em Flint (Michigan, EUA), que vivem em residências com condições inadequadas e ingerem água contaminada, apresentavam maiores concentrações de $\mathrm{Pb}$ no sangue e a intoxicação por este metal agravou fatores de estresse social como a pobreza, violência, desemprego e insegurança alimentar.

Em termos gerais Davis e Hirji (2003) advertem que em regiões áridas e semiáridas a salinidade é um dos parâmetros mais preocupantes na irrigação, principalmente devido a acumulação de sal na região das raízes o que acarreta perda de rendimento e em casos extremos pode ser responsável pela eliminação de toda a cobertura vegetal. A partir disto percebesse na tabela 6 , que o valor de CE em M1, M2 e M3 apresentam maior potencial de restrição por ultrapassar os limites de qualidade estabelecidos. Foi também nestas estações de amostragem que os metais Cd (estações de amostragem M1, M2 e M3) e Cu (M1) apresentaram comportamento semelhante. Para descrever o cenário local da agricultura foram usados os dados do no censo agrário de 2009 (IBGE, 2009), neste verificou-se que a maioria dos empreendimentos rurais registrados desenvolviam atividades agrícola de subsistência. Nos dados mais recentes do IBGE (2016) verificou-se em ordem decrescente que a mandioca ( $M a-$ nihot esculenta), o milho (Zea mays) e o feijão (Phaseolus vulgaris) foram as três culturas com maior área plantada ou destinada à colheita, e com aproximadamente $42 \mathrm{mil} /$ Toneladas colhidas a $M$. esculenta consolida-se como a protagonista destas culturas. Por isto, o presente estudo considerou esta cultura, nas avaliações das possíveis restrições e impactos do uso dos reservatórios estudados.

Segundo Gleadow et al., (2016) plantas estáveis de M. esculenta são mais tolerantes a $\mathrm{NaCl}$ do que plantas jovens, estas tiveram seu crescimento severamente retardado ao serem expostas a $40 \mathrm{mM} \mathrm{NaCl}$, enquanto que nos estáveis, efeitos adversos foram verificados apenas na exposição a $100 \mathrm{mM} \mathrm{NaCl}$. Tal comportamento também foi descrito por Araujo et al., (2015), ao avaliar o estresse salino à diferentes genótipos de M. esculenta, verificou uma redução no desenvolvimento in vitro das variedades de mandioca Lagoão e 'BRS Verdinha', a variedade mais tolerante foi a formosa com um cultivo in vitro de 90 dias. Embora a salinidade seja um fator preocupante, Bouarfa et al. (2009) relatam a experiência Argelina e Tunisiana, a partir de mudança em suas práticas, que levaram em consideração o conhecimento adquirido in situ, fazendeiros alcançaram o manejo sustentável da salinidade.

Metais pesados são uma preocupação constante para ambientalistas e profissionais da saúde, no caso do $\mathrm{Pb}$ que apresentou teores acima dos limites de qualidade nas estações de amostragem M1, M2 e M3, o metal não tem nenhum papel biológico benéfico, em geral é assimilado nos ossos assim como o Cálcio. Mesmo que os teores de $\mathrm{Pb}$ correspondam a fenômenos naturais, vale registrar que em análise do sangue e do leite de vacas, Swarup et al. (2005) verificou que os teores de chumbo implicam em aumento dos riscos à saúde pública devido ao aumento das doses diárias, os riscos são ainda maiores para as crianças que consomem este produto. Para Cowan e Blakley (2016) embora não exista relação direta entre o consumo de carne e/ou leite contaminado por $\mathrm{Pb}$ e efeitos adversos a saúde humana, a introdução de $\mathrm{Pb}$ via cadeia alimentar deve ser prevenida. Além disso os autores apontam que efeitos agudos de envenenamento do gado por $\mathrm{Pb}$ implicam em perdas econômicas. $\mathrm{O}$ Cobre foi outro metal que apresentou teores acima dos critérios de qualidade aqui adotados, apenas na estação de amostragem M1. Segundo Vida et al. (2014) o cobre é metal que causa maior número de envenenamentos de animais de criação.

\section{Conclusão}

As condições pluviométricas até o período e na região estudada, eram semelhantes ao verificado em regiões de clima semiárido quente. Os pequenos reservatórios de água superficial estudados, estavam situados em área agrícola com pouco potencial de impacto ambiental. Isto indica que os teores de metais nas amostras analisadas mesmo se classificados com contaminação e enriquecimento severo, são originados principalmente de processos naturais. As estações de amostragem com os maiores fatores de enriquecimento e índices de contaminação, cujo teores ultrapassavam os limites de qualidade adotados, estão posicionadas ao longo da sub-bacia do rio do Mudo.

Para os critérios de proteção de vida aquática, observou-se nas estações de amostragem M1, M2 e M3 toxicidade aguda (letalidade), provavelmente relacionada a elevada salinidade, que age nestes reservatórios como um fator limitante natural. Nas estações de amostragem G1 e G3 para M. micrura e G3 e G4 para C. silvestrii, verificou-se efeito crônico sobre a reprodução destes organismos testes, estas observações estão provavelmente relacionadas aos elevados teores de $\mathrm{Cd}, \mathrm{Pb}, \mathrm{Cu}, \mathrm{Zn}$ e $\mathrm{Cl}^{-}$.

Enquanto que para os critérios do uso da água para consumo humano o metal que trás maiores preocupações, caso seja necessário recorrer aos recursos hídricos dos reservatórios estudados é o $\mathrm{Pb}$. Já na agricultura, os riscos maiores estão relacionados a salinidade das estações de amostragem M1, M2 e M3. E no que diz respeito a dessedentação de animais o chumbo e o cobre são as maiores preocupações.

Assim foi mostrado que em períodos de estiagem prolongada, como a vivenciada nos últimos anos na região estudada, podem exigir medidas drásticas para sobrevivência socioeconômica e qualidade ambiental. Tais como o manejo adequado da água usada na irrigação, purificação da água por processos de dessalinização, estes últimos podem inclusive caso não planejados e executados da forma adequada, agravar processos de contaminação ambiental. 


\section{Referências}

ALVARES, C. A., STAPE, J. L., SENTELHAS, P. C., DE MORAES GONÇALVES, J. L., \& SPAROVEK, G. Köppen's climate classification map for Brazil. Meteorologische Zeitschrift, 2013, 22(6), 711-728. http://doi.org/10.1127/09412948/2013/0507

ALVES, R. I. S., SAMPAIO, C. F., NADAL, M., SCHUHMACHER, M., DOMINGO, J. L., \& SEGURAMUÑOZ, S. I. Metal concentrations in surface water and sediments from Pardo River, Brazil: Human health risks. Environmental Research, 2014, 133, 149-155. http://doi. org/10.1016/j.envres.2014.05.012

ANGELIM, L.A.A., MEDEIROS, V.C., NESI, J.R. Programa Geologia do Brasil - PGB. Projeto Mapa Geológico e de Recursos Minerais do Estado do Rio Grande do Norte. Mapa Geológico do Estado do Rio Grande do Norte. Escala 1:500.000. Recife: CPRM/FAPERN, 2006.

APRILE, F. M., \& BOUVY, M. Heavy metal levels in surface waters from a tropical river basin, Pernambuco State, northeastern Brazil. Acta Scientiarum. Biological Sciences, 2010, 32(4), 357-364. http://doi.org/10.4025/actascibiolsci. v32i4.5231

ARAUjO A. G., CARDOSO M. N., CRUZ F. E. M., LÉDO A. S., OLIVEIRA S. D. S., MIRANDA I. C. D. Salinidade in vitro de diferentes variedades de mandioca In: SEMINÁRIO DE INICIAÇÃO CIENTÍFICA E PÓS-GRADUAÇÃO DA EMBRAPA TABULEIROS COSTEIROS, 5., 2015, Aracaju. Anais. Brasília, DF: Embrapa, 2015. p. 280. ref. 6069 Disponível em: https://ainfo.cnptia.embrapa.br/digital/ bitstream/item/131029/1/Salinidade.pdf

AYERS, R., WESTCOT, D. Food, Agriculture Organization of the United Nations (FAO), Water Quality for Agriculture, Irrigation and Drainage, Rome, 1994, 29. Rev. 1, M-56. ISBN 92-5-102263-1

AZEVEDO-FILHO, J.B., MELO, J.V., LIMA, R.F.S. Avaliação da influência de íons metálicos em sedimento de fundo da bacia hidrográfica do rio Doce, RN-Brasil. Química no Brasil, 2012, 06(1-2), p45-54.

BARBOSA, J. S., CABRAL, T. M., FERREIRA, D. N., AGNEZLIMA, L. F., BATISTUZZO DE MEDEIROS, S. R. Genotoxicity assessment in aquatic environment impacted by the presence of heavy metals. Ecotoxicology and Environmental Safety, 2010,73(3), p320-325. http://doi.org/10.1016/j.ecoenv.2009.10.008

BELANGER, S. E., FARRIS, J. L., CHERRY, D. S. Effects of diet, water hardness, and population source on acute and chronic copper toxicity to ceriodaphnia dubia. archives of environmental contamination and toxicology, 1989, 18, p601-611.
LIMA, C. S., BARBOSA, P. T., LIRA, G. A. S. T., MOLICA, R. J. R. Cyanotoxin production and phylogeny of benthic cyanobacterial strains isolated from the northeast of Brazil. Harmful Algae, 2015, 43, p46-57. http://doi.org/10.1016/j. hal.2015.01.003

BOUARFA S., MARLET S., DOUAOUI A., HARTANI T., MEKKI I., GHAZOUANI W., BEN AISSA I., VINCENT B., HASSANI F., KUPER M., Salinity patterns in irrigation systems, a threat to be demystified, a constraint to be managed: field evidence from Algeria and Tunisia. Irrig. and Drain. 2009. 58, p273-284 DOI: 10.1002/ird.524.

CCME. Canadian Water Quality Guidlines. Canadian Environmental Quality Guidelines, 2008, p1484.

CCME. Canadian Water Quality Guidelines for the Protection of Aquatic Life, 2014, 11. Disponivel em: http://ceqg-rcqe. ccme.ca/download/en/148/

CLESCERI, L.; GREENBERG, A. E.; TRUSSELL, R. R. Standard methods for water and wastewater examination. APHA: New York, 1989.

COOPER, N. L., BIDWELL, J. R., KUMAR, A. Toxicity of copper, lead, and zinc mixtures to Ceriodaphnia dubia and Daphnia carinata. Ecotoxicology and Environmental Safety, 2009, 72(5), 1523-1528. http://doi.org/10.1016/j. ecoenv.2009.03.002

COWAN V., BLAKLEY B., Acute lead poisoning in western Canadian cattle - A 16-year retrospective study of diagnostic case records. Canadian Veterinary Journal. 2016, 57(4), p421426.

CRAWLEY, J. M., Statistics: An introduction using R. Jhon Wiley \& Sons, England. 2005, 337p. ISBN 0-47-02298-1

DAUVALTER, V., ROGNERUD, S. Heavy metal pollution in sediments of the Pasvik River drainage. Chemosphere, 42(1), 9-18. http://doi.org/10.1016/S0045-6535(00)00094-1

DAVIS R, HIRJI R. Irrigation and Drainage Development in Water Resources and Environment. The World Bank: Washington, DC. 2003, Ed.1, p36.

DAVIS, A. M., HOLLAND, H. D., TUREKIAN, K. K. Treatise on Geochemistry, 2003, 1. http://doi.org/10.1073/ pnas.0703993104

DINIZ, L. P., ELMOOR-LOUREIRO, L. M. A., ALMEIDA, V. L. DOS S., MELO JÚNIOR, M. Cladocera (Crustacea, Branchiopoda) of a temporary shallow pond in the Caatinga of Pernambuco, Brazil. Nauplius, 2013, 21(211), 104-6497. http://doi.org/10.1590/S0104-64972013000100008

DO HONG, L. C., BECKER-VAN SLOOTEN, K., 
TARRADELLAS, J. Tropical ecotoxicity testing with Ceriodaphnia cornuta. Environmental Toxicology, 2004, 19(5), 497-504. http://doi.org/10.1002/tox.20055

ELMOOR-LOUREIRO, L. M. A. Manual de Identificação de Cladóceros Límnicos do Brasil. Editora Universa. Universidade Católica de Brasília, 1997, 1, 155.

ELPHICK, J. R. F., BERGH, K. D., BAILEY, H. C. Chronic toxicity of chloride to freshwater species: Effects of hardness and implications for water quality guidelines. Environmental Toxicology and Chemistry, 2011, 30(1), 239-246. http://doi. org/10.1002/etc.365

FAUSTINO, A. B., RAMOS, F. F., SILVA, S. M. P. DA. Dinâmica temporal do uso e cobertura do solo na Bacia Hidrográfica do Rio Doce (RN) com base em Sensoriamento Remoto e SIG: uma contribuição aos estudos ambientais. Sociedade E Território, 2014, 26(2), p18-30. Retrieved from https://periodicos.ufrn.br/sociedadeeterritorio/article/ view/5305/4318

FERRÃO-FILHO, A. D S., SOARES, M. C. S., DE FREITAS MAGALHÃES, V., AZEVEDO, S. M. F. O. Biomonitoring of cyanotoxins in two tropical reservoirs by cladoceran toxicity bioassays. Ecotoxicology and Environmental Safety, 2009, 72(2), p479-489. http://doi.org/10.1016/j.ecoenv.2008.02.002

FORSTNER, U., WITTMANN, G. T. W. Metal Pollution in the Aquatic Environment, Springer- Verlag, Berlin, Heidelberg, 1981, p486.

GLEADOW R, PEGG A., BLOMSTEDT C. K., Resilience of cassava (Manihot esculenta Crantz) to salinity: implications for food security in low-lying regions. Journal of Experimental Botany. 2016, 67(18), pp. 5403-5413,

GOLDSCHMIDT V. M. The Principles of Distribution of Chemical Elements in Minerals and Rocks. Journ. Chemical Soc. pp. 655-673.Geological Magazine, 1937, 74(9), p428-429. doi:10.1017/S0016756800087847.

GOMES, W. K. A. M., SOUZA, R. F. DE S., MEDEIROS, G. F., CRISPIM, M. C. Resposta ecotoxicológica e parâmetros físicos e químicos em rio de área costeira do nordeste brasileiro. Gaia Scientia, 2016a, 10(4), p195-208.

GOMES, W. K. A. M., SOUZA, R. F., CRISPIM, M. C. Avaliação espacial e temporal da qualidade da água em rio de área costeira do nordeste brasileiro. Geo. Temas, 2016b, 6(2), p3-13.

HANNA-ATTISHA M., LACHANCE J., SADLER R. C., CHAMPNEY SCHNEPP A. Elevated blood lead levels in children associated with the Flint drinking water crisis: a spatial analysis of risk and public health response. Am J Public Health 2016, 106, p283-290.

HYNE, R. V, PABLO, F., JULLI, M., MARKICH, S. J. Influence of water chemistry on the acute toxicity of copper and zinc to the cladoceran Ceriodaphnia of dubia. Environmental Toxicology and Chemistry / SETAC, 2005, 24(7), 1667-1675. http://doi.org/10.1897/04-497r.1

IBGE (INSTITUTO BRASILEIRO DE GEOGRAFIA E ESTATÍSTICA). CENSO DEMOGRÁFICO 2010. Características da população e dos domicílios: resultados do universo. Rio de Janeiro: IBGE, 2011. Disponivel em: https:// cidades.ibge.gov.br/v4. Acesso em: 03. Jun. 2018

IBGE (INSTITUTO BRASILEIRO DE GEOGRAFIA E ESTATÍSTICA). Censo Agropecuário 2006. Rio de Janeiro: IBGE, 2009. Disponível em: https://biblioteca.ibge.gov.br/ visualizacao/periodicos/51/agro_2006.pdf Acesso em: 03. Jun. 2018

IBGE (INSTITUTO BRASILEIRO DE GEOGRAFIA E ESTATÍSTICA). Produção agrícola municipal: culturas temporárias e permanentes. - Tabelas completas. Rio de Janeiro, 2016. Disponível em: https://www.ibge.gov.br/estatisticasnovoportal/economicas/agricultura-e-pecuaria/9117producao-agricola-municipal-culturas-temporarias-epermanentes.html edicao $=16787 \& \mathrm{t}=$ downloads. Acesso em: 02. jun. 2018.

INMET (INSTITUTO NACIONAL DE METEOROLOGIA). Estações Meteorológicas OMM:82596; 82690; 82598 Disponível em: http://www.inmet.gov.br/projetos/rede/pesquisa/inicio.php Acesso em: 4. Jun. 2018.

KOTTEK, M., GRIESER, J., BECK, C., RUDOLF, B., RUBEL, F. World map of the Köppen-Geiger climate classification updated. Meteorologische Zeitschrift, 2006, 15(3), 259-263. http://doi.org/10.1127/0941-2948/2006/0130

MARENGO, J. A., BERNASCONI, M. Regional differences in aridity/drought conditions over Northeast Brazil: present state and future projections. Climatic Change, 2015, 129(1-2), 103-115. http://doi.org/10.1007/s10584-014-1310-1

MARENGO, J. A., TORRES, R. R., ALVES, L. M. Drought in Northeast Brazil - past, present, and future. Theoretical and Applied Climatology, 2016, 1-12. http://doi.org/10.1007/ s00704-016-1840-8

MELO, J. G., MORAIS, S. D. O., VASCONCELOS, M. B., Potencialidade e qualidade das águas do Aquifero Barreiras na região da Lagoa de Extremoz, RN. Revista de Geologia, 2010, 22(2), 137-149.

MELO, J. G., VASCONCELOS, M. B., MORAIS, S. D. O., ALVES, R. S. Avaliação Hidrogeológica da Zona Norte da Cidade de Natal e os Problemas Associados ao Desenvolvimento Urbano. Revista Brasileira de Recursos Hídricos, 2012, 17(1), 123-134.

MOURA, W. K. A. Horticultura no baixo curso do Rio Doce, 
Zona Norte do Natal/RN: Avaliação da qualidade da água. Natal, 2011. Dissertação de mestrado - Programa Regional de Pós-Graduação em Desenvolvimento e Meio Ambiente - PRODEMA/UFRN. Universidade Federal do Rio Grande do Norte, Natal.

MOURA, W. K. A. ; SOUZA, R. F. ; SOUZA, C. R. ; PETTA, R. A.; DINIZ FILHO, J. B. Algumas implicações ambientais da horticultura na região do baixo curso do rio doce, zpa-9, zona norte do natal/rn. In: Maria de Fátima Freire de Melo Ximenes; Raquel Franco de Souza. (Org.). Meio ambiente e saúde humana: práticas, vivências e saberes. 2013, 1ed.Natal: EDUFRN, p. 221-242.

NADDY, R. B., COHEN, A. S., STUBbLEFIELD, W. A. The interactive toxicity of cadmium, copper, and zinc to Ceriodaphnia dubia and rainbow trout (Oncorhynchus mykiss). Environmental Toxicology and Chemistry, 2015, 34(4), 809-815. http://doi.org/10.1002/etc.2870

NOBREGA, T. F. Monitoramento ecotoxicológico de água e sedimento em reservatório urbano localizado na região litorânea do Nordeste Brasileiro. 2015, [Dissertation] Universidade Federal do Rio Grande do Norte. Centro de Biocências. Programa Regional de Pós-Graduação em Desenvolvimento e Meio Ambiente/PRODEMA. $91 \mathrm{f}$.

NOBREGA T. F., SOUZA R. F., MEDEIROS G. F. Avaliação ecotoxicológica de água e sedimento de um reservatório de água urbano e costeiro do nordeste brasileiro. Revista Ambiência. 2017, 13(2)., p. 393 - 411. DOI:10.5935/ambiencia.2017.02.09

RStudio Team. RStudio: Integrated Development for R. RStudio, Inc., Boston, MA, 2016, Disponivel em: http://www. rstudio.com/.

SISINNO, C. L. S., OLIVEIRA-FILHO E. C., Princípios de Toxicologia Ambiental, Editora Interciência. Rio de Janeiro, Brasil. 2013, p198.

SOARES, C. E. A., ELMOOR-LOUREIRO, L. M. A. Uma atualização da lista de Cladocera Cladocera (Crustacea, Branchiopoda) do Estado de Pernambuco, Brasil. Biota Neotropica, 2011, 11(2), p409-414. http://doi.org/10.1590/ S1676-06032011000200038

SOFYAN, A., ROSITA, G., PRICE, D. J., BIRGE, W. J. Cadmium Uptake By Ceriodaphnia Dubia From Different Exposures: Relevance To Body Burden and Toxicity. Environmental Toxicology and Chemistry, 2007, 26(3), p470. http://doi. org/10.1897/06-232R.1

SWARUP D., PATRA R. C., NARESH R., KUMAR P., SHEKHAR P. Blood lead levels in lactating cows reared around polluted localities; transfer of lead into milk. Science of the Total Environment, 2005, 349, p67-71.

VIDA. Veterinary Investigation Diagnosis Analysis. In: Veterinary Investigation Surveillance Report TABLE 5:
SHEEP 2007-2014. Animal \& Plant Pealth Agency. UK. 2014. p17.

VILAR, M. C. P., ARAÚJO-CASTRO, C. M. V., MOURA, A. N. Acute toxicity of Microcystis spp. (Cyanobacteria) bloom on Moina minuta (Cladocera) in a tropical reservoir, Northeastern Brazil. Ecotoxicology and Environmental Contamination. 2014, 9(1), p93-98. http://doi.org/10.5132/ eec.2014.01.012

WELSH, P. G., LIPTON, J., CHAPMAN, G. A., PODRABSKY, T. L. Relative importance of calcium and magnesium in hardness-based modification of copper toxicity. Environmental Toxicology and Chemistry, 2000, 19(6), p1624-1631. http://doi. org/10.1897/1551-5028(2000)019<1624:RIOCAM >2.3.CO;2

WORLD HEALTH ORGANIZATION (WHO). Guidelines for Drinking-water Quality, 2012, 4ed, ISBN 9789241548151.

YONGMING, H.; PEIXUAN D.; JUNJI C.; POSMENTIER E.S. Multivariate analysis of heavy metal contamination in urban dusts of Xi'an, Central China. Science of the Total Environment, Amsterdam. 2006, 355. p176-186.

ZAGATTO, P.A., BERTOLETTI E. (EE). Ecotoxicologia Aquática: Princípios e Aplicações. 2014, 2ed. Rima. p472.

ZALIZNIAK, L., KEFFORD, B. J., NUGEGODA, D. Is salinity all the same? 1. the effect of ionic compositions on the salinity tolerance of five species of freshwater invertebrates. Marine and Freshwater Research, 2006, 57, p75-82.

ZOU, E., BU, S. Acute toxicity of copper, cadmium, and zinc to the water flea, Moina irrasa (Cladocera). Bulletin of Environmental Contamination and Toxicology. 1994, 52(5). p742-748. http://doi.org/10.1007/BF00195497

\section{Contribuição dos autores}

Thiago Farias Nobrega

Contribuições substanciais para a concepção do trabalho; aquisição: análise e interpretação de dados; redigiu o trabalho e realizou uma revisão substancial.

\section{Raquel Franco Souza}

Contribuições substanciais para a concepção do trabalho; aquisição; análise e interpretação de dados; redigiu o trabalho e realizou uma revisão substancial.

Guilherme Fulgencio Medeiros

Contribuições substanciais para a concepção do trabalho; aquisição; análise e interpretação de dados. 